\title{
Weakened Anomalous Western North Pacific Anticyclone during an El Niño-Decaying Summer under a Warmer Climate: Dominant Role of the Weakened Impact of the Tropical Indian Ocean on the Atmosphere
}

\author{
CHAO HE \\ Institute for Environmental and Climate Research, Jinan University, Guangzhou, China \\ TIANJUN ZHOU \\ State Key Laboratory of Numerical Modeling for Atmospheric Sciences and Geophysical Fluid Dynamics (LASG), \\ Institute of Atmospheric Physics, Chinese Academy of Sciences, Beijing, China \\ TIM LI \\ Key Laboratory of Meteorological Disaster of Ministry of Education, Nanjing University of \\ Information Science and Technology, Nanjing, China
}

(Manuscript received 19 January 2018, in final form 7 August 2018)

\begin{abstract}
The western North Pacific subtropical anticyclone (WNPAC) is the most prominent atmospheric circulation anomaly over the subtropical Northern Hemisphere during the decaying summer of an El Niño event. Based on a comparison between the RCP8.5 and the historical experiments of 30 coupled models from the CMIP5, we show evidence that the anomalous WNPAC during the El Niño-decaying summer is weaker in a warmer climate although the amplitude of the El Niño remains generally unchanged. The weakened impact of the sea surface temperature anomaly (SSTA) over the tropical Indian Ocean (TIO) on the atmosphere is essential for the weakened anomalous WNPAC. In a warmer climate, the warm tropospheric temperature (TT) anomaly in the tropical free troposphere stimulated by the El Niño-related SSTA is enhanced through stronger moist adiabatic adjustment in a warmer mean state, even if the SSTA of El Niño is unchanged. But the amplitude of the warm SSTA over TIO remains generally unchanged in an El Niño-decaying summer, the static stability of the boundary layer over TIO is increased, and the positive rainfall anomaly over TIO is weakened. As a result, the warm Kelvin wave emanating from TIO is weakened because of a weaker latent heating anomaly over TIO, which is responsible for the weakened WNPAC anomaly. Numerical experiments support the weakened sensitivity of precipitation anomaly over TIO to local SSTA under an increase of meanstate SST and its essential role in the weakened anomalous WNPAC, independent of any change in the SSTA.
\end{abstract}

\section{Introduction}

In the decaying summer of an El Niño event (i.e., half a year after the peak phase of El Niño in boreal winter), the subtropical western North Pacific (WNP) is usually controlled by a large-scale anticyclone anomaly (e.g., Zhang et al. 1999; Li et al. 2017; Zhang et al. 2017). This anomalous anticyclone is called the western North

Supplemental information related to this paper is available at the Journals Online website: https://doi.org/10.1175/JCLID-18-0033.s1.

Corresponding author: Dr. Chao He, hechao@jnu.edu.cn
Pacific anticyclone (WNPAC), and it forms in the winter of the peak phase of El Niño and persists into the decaying summer after El Niño (Wang et al. 2000; Stuecker et al. 2015; Wu et al. 2017). In summer, the anomalous WNPAC modulates water vapor transport into East Asia and brings excessive rainfall along the Yangtze River valley, but deficient rainfall in both South China and North China (Chang et al. 2000; Li et al. 2014; Zhang et al. 2016; Zhang et al. 2017).

El Niño usually peaks in winter and decays in spring, and most El Niño events disappear in the summer of its decaying year. Because the atmosphere responds quickly to underlying SST anomalies, and the memory of the atmosphere is shorter than 1 month, how does the 
anomalous WNPAC maintain from the peak phase of El Niño in winter to its decaying summer? Great efforts have been devoted to the investigation of the maintenance mechanism of the WNPAC in the past decade in the context of both data diagnosis and model simulations, and the tropical Indian Ocean (TIO) has been found to play an essential role (e.g., Sui et al. 2007; Yang et al. 2007; Li et al. 2008; Xie et al. 2009; Wu et al. 2009a; Song and Zhou 2014a,b; Wu et al. 2017). Passively forced by El Niño, the SST anomaly (SSTA) over TIO become warmer from boreal winter to spring during the El Niño-decaying phase, resembling the recharge process of a capacitor. In the following summer, when El Niño has already dissipated, warm SSTA in the TIO plays an important role in forcing the anomalous WNPAC, similar to the discharge process of a capacitor (Li et al. 2008; Wu et al. 2009a; Xie et al. 2009, 2016).

In summer, warm SSTAs in the TIO stimulate a warm Kelvin wave, with easterly wind anomalies in the deep tropics from the Indian Ocean to the western Pacific and anticyclonic wind shear on its northern and southern flanks. The anticyclonic relative vorticity anomaly in the free troposphere of the WNP further induces divergence in the Ekman layer (i.e., wave-induced Ekman divergence), which suppresses local precipitation and latent heating and further enhances the anomalous WNPAC (Terao and Kubota 2005; Li et al. 2008; Wu et al. 2009a; Xie et al. 2009, 2016). Tropospheric temperature (TT) anomalies have been widely used to measure the Kelvin waves emanating from the TIO (e.g., Xie et al. 2009; Chowdary et al. 2012; Hu et al. 2014). In addition to the TIO, SST anomalies over several other tropical oceans have also been thought to contribute to the maintenance of the WNPAC in summer, such as the equatorial Pacific (Chen et al. 2012; Wang et al. 2013; Z. Chen et al. 2016), the WNP (Sui et al. 2007; Wu et al. 2010), and the tropical Atlantic Ocean (Rong et al. 2010; Hong et al. 2014). Key oceanic regions responsible for the summertime WNPAC anomaly and their mechanisms are reviewed in several recent papers (He et al. 2015; Li et al. 2017; Zhang et al. 2017).

The interannual relationship between the WNPAC and ENSO can be affected by both internal decadal variability and anthropogenic greenhouse gas forcing. The response of the TIO SST anomaly to El Niño and the impact of TIO SST anomalies on the WNPAC have experienced significant decadal changes in the late 1970s (Huang et al. 2010; Xie et al. 2010; Chakravorty et al. 2014) and early 1990s (He and Zhou 2015; Gu et al. 2017; Chen et al. 2017). Internal decadal variability has been demonstrated to play an active role in modulating the decadal change of interannual WNPAC variability (Chowdary et al. 2012; Song and Zhou 2015). The impact from strong internal variability and the associated uncertainty should be accounted for when investigating the response of the anomalous WNPAC to global warming under anthropogenic greenhouse gas (GHG) forcing.

Ensemble simulation of fully coupled climate system models is an effective way to separate the forced response from the decadal oscillation induced by internal variability. Analysis based on multimodel experiments from phase 5 of the Coupled Model Intercomparison Project (CMIP5; Taylor et al. 2012) show that positive TT anomalies during El Niño will be amplified, because of enhanced moist adiabatic adjustment of the atmosphere under a moister mean state (Hu et al. 2014; Tao et al. 2015). Despite the great importance of the anomalous WNPAC to the abnormal climate over East Asiawest Pacific in summer, the possible response of the anomalous WNPAC during the El Niño-decaying summer to global warming remains inconclusive (Zheng et al. 2011; W. Chen et al. 2016; Jiang et al. 2018). We aim to answer the following questions in this study: How does the anomalous WNPAC during the El Niño-decaying summer change in a warmer climate? Which physical processes are responsible for its change?

The remainder of this paper is organized as follows. The model, data, and analysis methods are introduced in section 2. The projected changes in the anomalous WNPAC during the El Niño-decaying summer and the sensitivity of the WNPAC to SST anomalies in the TIO are addressed in section 3. The underlying physical process for the change in the sensitivity of the WNPAC to SST anomalies is addressed in section 4. Finally, the conclusions are summarized in section 5 with a discussion.

\section{Model, data, and methods}

In total, 30 models from CMIP5 are adopted for analyses in this study (see Table $\mathrm{S} 1$ in the online supplemental material). The historical experiments of the CMIP5 models are forced by observed historical external forcing (e.g., GHG and aerosols) (Taylor et al. 2012), and the 1950-99 period in the historical experiment is used to represent the baseline climate, referred to as "20C." The representative concentration pathway 8.5 (RCP8.5) experiment from CMIP5 is forced by a high emission pathway, which is equivalent to a radiative forcing of $8.5 \mathrm{~W} \mathrm{~m}^{-2}$ in the year 2100 (van Vuuren et al. 2011). The 2050-99 period in the RCP8.5 experiment (referred to as 21C) is adopted to represent a warmer climate in the future. The $21 \mathrm{C}$ in RCP8.5 experiment is compared with the $20 \mathrm{C}$ in the historical experiment. For each model, only one realization is used to give equal weight to each model. In addition to the model data, the 
following observational and reanalysis datasets spanning from 1948 to 2017 are also used in our analysis: 1) monthly wind, geopotential height, and vertical velocity from the National Centers for Environmental PredictionNational Center for Atmospheric Research (NCEPNCAR) (Kalnay et al. 1996) and 2) monthly SST from the NOAA Extended Reconstructed SST dataset (ERSST), version 5 (B. Huang et al. 2017).

A high concentration pathway of RCP8.5 is analyzed in this study since internal climate variability has a profound impact on decadal climate change (Deser et al. 2012; Chowdary et al. 2012; Song and Zhou 2015; Chen and Zhou 2018) and the GHG-forced circulation change can be easily extracted from internal variability in RCP8.5. We have also analyzed the RCP4.5 experiment and the results are similar to those in RCP8.5 if the projected change is scaled by the magnitude of meanstate warming. For simplicity, the symbols $\Delta$ and $\delta$ are used to denote the absolute and relative changes in variable $X$ per $1 \mathrm{~K}$ of tropical averaged surface warming, that is, $\Delta X=\left(X^{21 \mathrm{C}}-X^{20 \mathrm{C}}\right) /\left(T^{21 \mathrm{C}}-T^{20 \mathrm{C}}\right)$ and $\delta X=$ $\Delta X / X^{20 \mathrm{C}}$, respectively. Here, $T^{20 \mathrm{C}}$ and $T^{21 \mathrm{C}}$ denotes the annual mean of the tropical $\left(30^{\circ} \mathrm{S}-30^{\circ} \mathrm{N}\right)$-averaged surface temperature for $20 \mathrm{C}$ in the historical experiment and $21 \mathrm{C}$ in the RCP8.5 experiment, respectively. The multimodel median of $T^{21 \mathrm{C}}-T^{20 \mathrm{C}}$ is $2.83 \mathrm{~K}$.

Since we focus on interannual variability, all data are subject to an 8-yr high-pass Fourier filter in this study, which allows the low-frequency variability to be removed, and only the interannual variability is retained. Regression slopes of atmospheric circulation anomalies onto SST indices (e.g., the Niño-3.4 index or the TIO-SST index) are adopted to measure the sensitivity of the circulation anomalies to SST anomalies. The regression slope is calculated for each model, and the multimodel median (MMM) is obtained. We adopt the median value instead of the mean value because the median is more robust and less affected by outliers (Gleckler et al. 2008). The intermodel consistency (or uncertainty) is evaluated in terms of the percentage of individual models that agree in sign with the MMM-projected change. According to Power et al. (2012), a 95\% confidence level based on the $t$ test is equivalent to an intermodel consistency of $68 \%$ under the assumption of independency among the models. Therefore, an intermodel consistency greater (less) than $70 \%$ is regarded as robust (uncertain) among the models in this study.

The linear baroclinic model (LBM) and the Community Atmosphere Model, version 5 (CAM5), are adopted in this study to investigate the mechanism. The LBM is a primary equation model developed by Watanabe and Kimoto (2000), which is used to test the response of the anomalous atmospheric circulation to the diabatic heating anomaly. In this study, the LBM is run at a resolution of triangular truncation of T42, with 20 sigma levels in the vertical. CAM5 (Neale et al. 2012) is the atmospheric component of the Community Earth System Model (CESM), and is adopted here to test the TT and precipitation anomalies forced by prescribed SST boundary conditions. A finite-volume dynamic core with a horizontal resolution of about $1.9^{\circ}$ in latitude and $2.5^{\circ}$ in longitude is adopted for CAM5, with 30 levels in the hybrid sigma-pressure coordinate in the vertical.

\section{Projected changes of the anomalous WNPAC during an El Niño-decaying summer and its uncertainty}

An anomalous WNPAC is forced by the suppressed latent heating as a direct or indirect response to SST anomalies in the tropics. Therefore, the intensity of the anomalous WNPAC is modulated by two factors. The first factor is the amplitude of the SST anomaly itself. If the SST anomaly of El Niño is enhanced or if the SST anomaly over some key regions associated with El Niño (such as the warm SSTA over the TIO or the cold SSTA over WNP forced by El Niño) is enhanced in a warmer climate, a stronger WNPAC anomaly during an El Niño-decaying summer is expected, and vice versa. The second factor is the sensitivity of a WNPAC to a oneunit SST anomaly. Under a warmer climate, it may be possible that the SST anomalies associated with El Niño generally remain unchanged, but a one-unit SST anomaly could generate a much stronger or weaker diabatic heating anomaly and WNPAC anomaly (i.e., the WNPAC may become more or less sensitive to the SST anomaly). We examine the above two hypotheses in sections $3 \mathrm{a}$ and $3 \mathrm{~b}$.

\section{a. Projected changes in interannual SST variability}

The multimodel mean (MMM)-projected fractional change in the amplitude of interannual SST variability is shown in Fig. 1 for boreal winter (DJF), spring (MAM), and summer (JJA), where the amplitude of the interannual SST variability is measured by the standard deviation of the 8-yr high-pass-filtered time series. The interannual variability of the seasonal-mean SST is amplified over a large fraction of subtropical oceans, but the change is weak over the equatorial Pacific. Based on the MMM, the amplitude of the interannual variability of the Niño-3.4 index changes slightly by $-0.53 \%$ in winter, $+0.54 \%$ in spring, and $+1.69 \%$ in summer per $1 \mathrm{~K}$ of tropical warming, but a large intermodel uncertainty is evident; thus, the change is not in agreement with more than $70 \%$ of the individual models (Fig. 2). Given the small amplitude of change in the interannual 


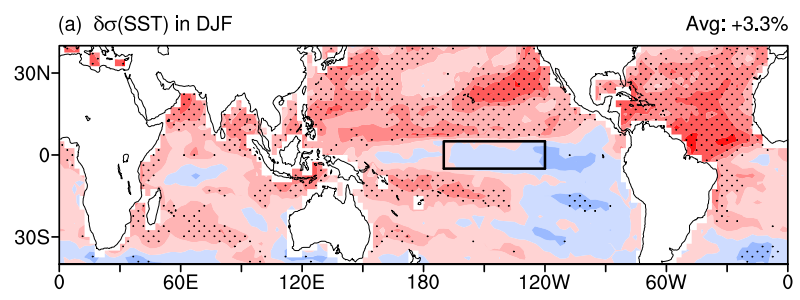

(b) $\delta \sigma$ (SST) in MAM

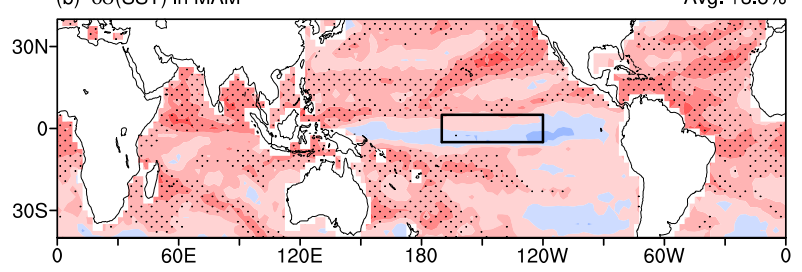

(c) $\delta \sigma(\mathrm{SST})$ in JJA

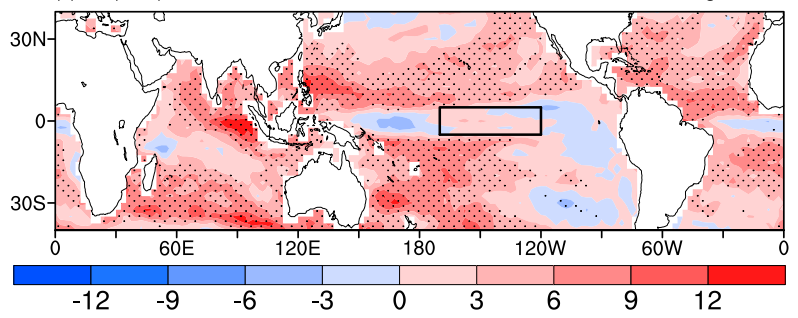

FIG. 1. The MMM-projected percentage of change in the interannual standard deviation (\%) of SST per $1 \mathrm{~K}$ of tropical surface warming. (a) Boreal winter (DJF), (b) boreal spring (MAM), and (c) boreal summer (JJA). The stippling indicates agreement by at least $70 \%$ of the individual models. The box is the region for the Niño-3.4 index.

variability of the Niño-3.4 index and its large intermodel uncertainty, the SST variability of ENSO itself can be considered as generally unchanged. This result is consistent with previous studies (e.g., Stevenson et al. 2012; Zheng et al. 2016), and the IPCC AR5 report states that the magnitude of SST variability in ENSO is likely to remain unchanged in the twenty-first century (IPCC 2013).

Despite the generally unchanged interannual SST variability over the equatorial Pacific, interannual SST variability over the other parts of the tropical and subtropical oceans outside the equatorial Pacific is amplified significantly (Fig. 1). The enhanced interannual SST variability may partly be explained by the teleconnection associated with ENSO. During El Niño, tropospheric temperature (TT) in the tropics warms because of a moist adiabatic adjustment. The underlying SST responds to the TT anomaly through surface heat fluxes, and most of the sea surface in the tropics is covered by warm SST anomalies (Chiang and Sobel 2002; Chiang and Lintner 2005). In a warmer climate, the warm TT anomalies forced by El Niño are enhanced because of stronger moist adiabatic adjustment in a moister atmosphere,

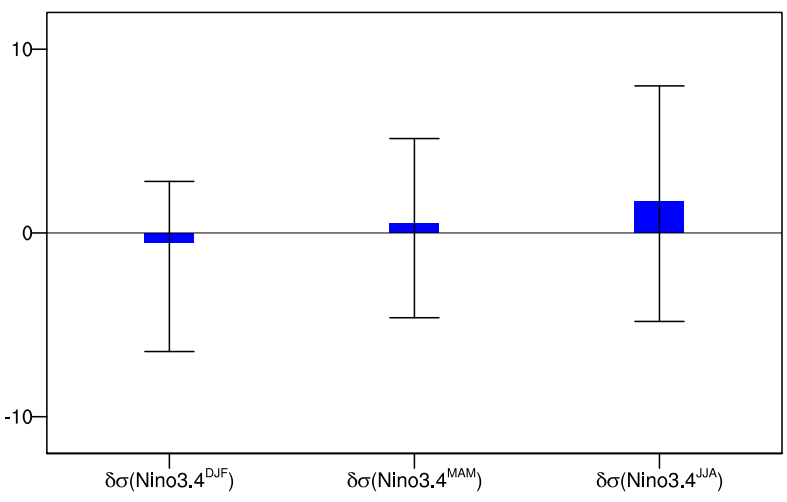

FIG. 2. Percentage changes (\%) in the interannual standard deviations of the Niño-3.4 index in DJF, MAM, and JJA. The blue bar indicates the MMM, and the thin black bar denotes the range between the 30th and 70th percentiles of the individual models.

and the warm SST anomalies over remote oceans are enhanced under the forcing of the stronger warm TT anomaly (Hu et al. 2014; Tao et al. 2015).

\section{b. Projected changes in the sensitivity of WNPAC to SST anomalies}

To evaluate anomalous atmospheric circulation over the WNP during a decaying El Niño and its response to global warming, the anomalies of geopotential height $H$, wind, and relative vorticity $\zeta$ at $850 \mathrm{hPa}$ in summer are regressed onto the DJF Niño-3.4 index for each model. The MMM of the regression slopes for $20 \mathrm{C}$ and $21 \mathrm{C}$, and their changes scaled by the tropical-mean warming, are shown in Fig. 3. For brevity, only the positive phase of the regression (i.e., the $\mathrm{El}$ Niño condition) is discussed; the negative phase (i.e., the La Niña condition) is vice versa and not discussed here.

The geopotential height anomaly at $850 \mathrm{hPa}$ (H850) during an El Niño-decaying summer is characterized by a positive anomaly center over the WNP south of $30^{\circ} \mathrm{N}$, which is associated with an anticyclonic wind anomaly, and a negative anomaly center over the midlatitudes in the North Pacific (approximately $35^{\circ}-50^{\circ} \mathrm{N}$ ) is associated with cyclonic wind anomalies. This meridional wave train pattern is named the Pacific-Japan (PJ) teleconnection pattern or the East Asian-Pacific (EAP) teleconnection pattern (Nitta 1987; Huang and Sun 1992). In addition to the PJ/EAP pattern and the anomalous WNPAC over the WNP, a notable feature is that the $\mathrm{H} 850$ over the entire tropics is characterized by positive anomalies with a spatially uniform pattern (Fig. 3a). This spatially uniform positive geopotential height anomaly results from positive temperature anomaly below it, because the difference of the geopotential height between a pressure level and the surface is proportional to temperature below it and the surface is fixed (Huang et al. 2015; Hu et al. 2018; He et al. 2018). 

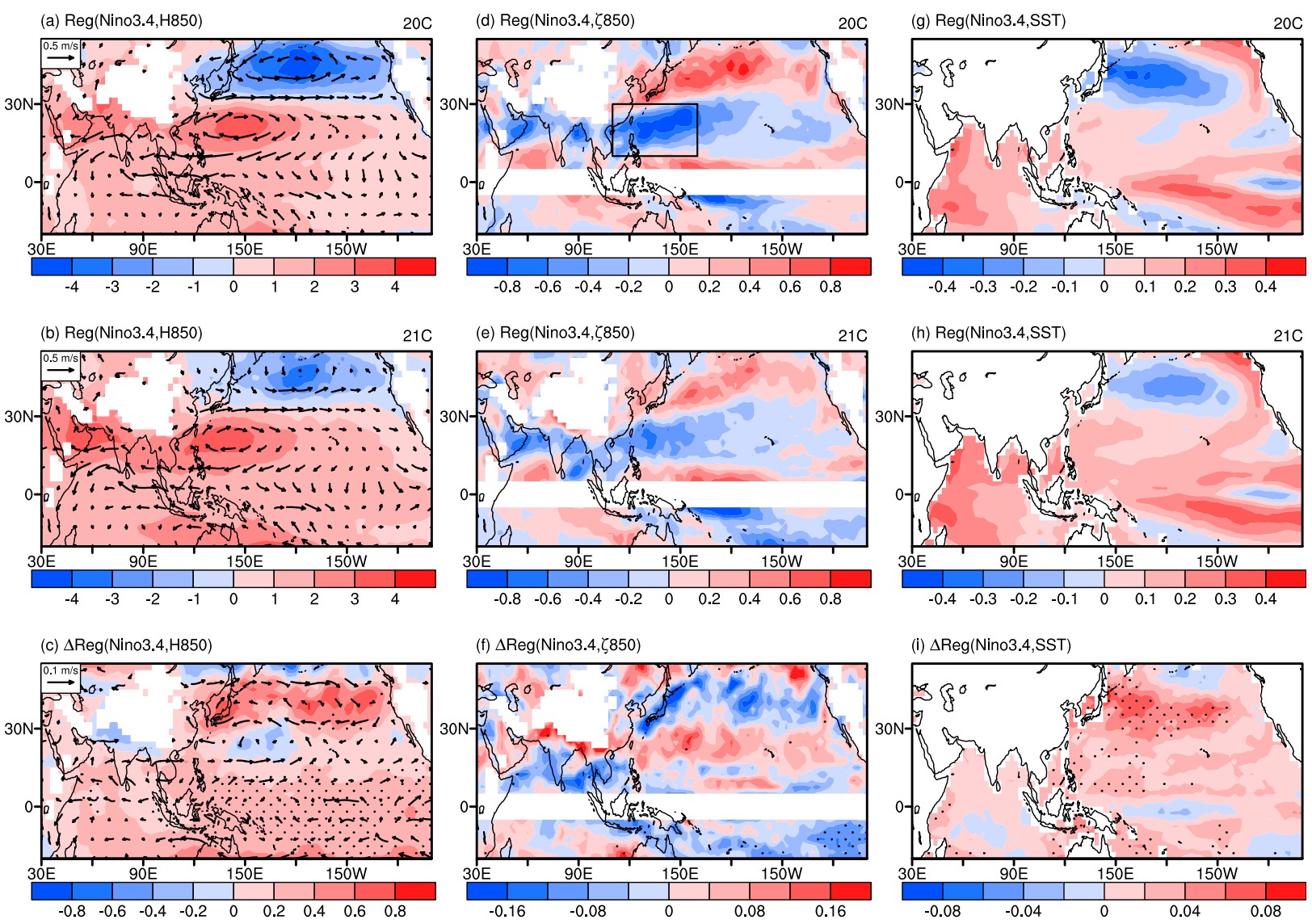

FIG. 3. Regressed anomalies in JJA onto the DJF Niño-3.4 index for (top) 20C and (middle) 21C, and (bottom) their differences scaled by tropical-mean warming. The regressed anomalies in JJA are (a)-(c) geopotential height and wind at $850 \mathrm{hPa}^{\left(\mathrm{gpm} \mathrm{K}^{-1} \text { and m s}\right.} \mathrm{K}^{-1}$, respectively), (d)-(f) relative vorticity at $850 \mathrm{hPa}\left(10^{-6} \mathrm{~s}^{-1} \mathrm{~K}^{-1}\right)$, and $(\mathrm{g})-(\mathrm{l}) \mathrm{SST}\left(\mathrm{K} \mathrm{K}^{-1}\right)$. In the bottom row, the stippling indicates agreement by at least $70 \%$ of the individual models.

The regressed anomalies in $21 \mathrm{C}$ from the RCP8.5 experiment share a similar spatial pattern with those in the 20C (Fig. 3b). Compared with the regression map in 20C (Fig. 3a), the locations of the WNPAC and PJ/EAP pattern anomaly centers remain generally unchanged in 21C (Fig. 3b). The difference between $21 \mathrm{C}$ and 20C (Fig. 3c, scaled by tropical-mean warming) is characterized by an increase in $\mathrm{H} 850$ anomaly over the tropics within $20^{\circ} \mathrm{S}-20^{\circ} \mathrm{N}$, a decrease in $\mathrm{H} 850$ anomaly over the WNP within $20^{\circ}-30^{\circ} \mathrm{N}$, and a substantial increase in H850 anomaly at midlatitudes over the North Pacific within approximately $35^{\circ}-50^{\circ} \mathrm{N}$. The increase in H850 over the deep tropics features a spatially uniform pattern, indicating that it is caused by an enhanced response of tropical TT to El Niño, which has little impact on changes in atmospheric circulation because circulation is determined by the horizontal gradient rather than the absolute magnitude of the geopotential height. Over the subtropical WNP (within $20^{\circ}-30^{\circ} \mathrm{N}$ ), the negative H850 and the cyclonic anomalies in Fig. 3c suggest a weakened anomalous WNPAC during an El Niño-decaying summer.
The cyclonic anomaly over the midlatitude North Pacific is also substantially weakened, indicating a weakened $\mathrm{PJ} / \mathrm{EAP}$ teleconnection.

The change in H850 anomalies is contributed by two components: the horizontally uniform increase in $\mathrm{H} 850$ induced by enhanced TT anomalies and the horizontally nonuniform component associated with wind ( $\mathrm{Hu}$ et al. 2018; He et al. 2018), and the change in the WNPAC anomaly is related to the latter component. To measure the anomalous WNPAC more objectively, we use relative vorticity at $850 \mathrm{hPa}(\zeta 850)$, which is a direct measure of the strength of a cyclone or an anticyclone. Relative vorticity has also been widely used to measure subtropical anticyclones (Terao and Kubota 2005; He and Zhou 2014; Huang et al. 2015; Wu and Zhou 2016). Figures $3 d-f$ show the regressed summertime $\zeta 850$ anomaly onto the DJF Niño-3.4 index for 20C, 21C, and the change. Consistent with the wind anomalies, the decaying summer of an El Niño event is usually associated with negative $\zeta 850$ values over the WNP (within $10^{\circ}-30^{\circ} \mathrm{N}$ ) and positive $\zeta 850$ values over the midlatitude 
North Pacific (within $35^{\circ}-50^{\circ} \mathrm{N}$ ) (Fig. 3d). In 21C, anomalously negative $\zeta 850$ values over the subtropical WNP and anomalously positive $\zeta 850$ values over midlatitudes in the North Pacific are both weaker than those in 20C (Fig. 3e), and the sign of change in the $\zeta 850$ anomalies (Fig. 3f) is generally opposite to the $\zeta 850$ anomalies in 20C (Fig. 3d); this also indicates a weaker WNPAC anomaly during an El Niño-decaying summer in a warmer climate. In summary, multiple variable changes consistently indicate a weakened WNPAC anomaly during an El Niño-decaying summer in a warmer climate.

Wintertime SST anomalies over the equatorial Pacific cannot exert direct forcing on the summertime WNPAC. Since SST anomalies in summer forced by ENSO are considered to have a direct forcing on the WNPAC, regressed summertime SST anomalies onto the DJF Niño-3.4 index for the $20 \mathrm{C}$ and $21 \mathrm{C}$ epochs are examined in Figs. 3g,h, and their differences scaled by tropical-mean surface warming are shown in Fig. 3i. In the decaying summer of an El Niño event, warm SST anomalies over the TIO are reproduced by the MMM (Fig. 3g), which is consistent with the SST anomalies from the observations (Xie et al. 2009). There is a weak warm SSTA over the subtropical WNP in JJA for both 20C and 21C (Figs. 3g,h), consistent with previous studies based on observations [Fig. 4 in Xie et al. (2009)] and the CMIP5 models [Figs. 2 and 4 of Jiang et al. (2018)], accompanied by local anticyclone anomaly. Although the cold SSTA over the subtropical WNP in early summer (June) of the El Niño-decaying phase contributes to the anomalous WNPAC by forcing a negative precipitation and latent heating anomaly over WNP (Wu et al. 2010), the seasonal-mean SSTA over WNP in JJA is forced by the atmosphere during the El Niño-decaying summer rather than forcing the atmosphere (Wu et al. 2009b). The cold SST anomaly over the midlatitude North Pacific is also a passive response to the local cyclone anomaly associated with the PJ/EAP wave train. Although there is warm SST anomaly over the tropical Pacific (Fig. 3g), it is not helpful for the maintenance of the WNPAC anomaly in an El Niñodecaying summer (Chen et al. 2012; Wang et al. 2013). In all, the tropical SST anomalies during the El Niñodecaying phase are well reproduced by the MMM of the models, and TIO SST anomalies play an essential role in the maintenance of the WNPAC anomaly.

In $21 \mathrm{C}$, summertime SST anomalies regressed onto the DJF Niño-3.4 index are generally featured by weakened negative SST anomalies over the midlatitudes in the North Pacific and enhanced positive SST anomalies in the other parts of the Indo-Pacific (Figs. $3 \mathrm{~h}$ and $3 \mathrm{i}$ ). This robust feature results from enhanced warm TT anomaly caused by enhanced moist adiabatic adjustment (Chiang and Lintner 2005; Hu et al. 2014; Tao et al. 2015). Over the subtropical Pacific south of $20^{\circ} \mathrm{N}$ the enhancement of the warm SST anomaly is generally uniform in the zonal direction (Fig. 3i), but the negative SST anomaly center over the midlatitude North Pacific is substantially weakened, suggesting the additional role of the reduced intensity of the local anomalous cyclone associated with the PJ/EAP wave train. The positive SST anomaly over the TIO is slightly enhanced (Fig. 3i) but insignificant in terms of the intermodel uncertainty.

Although the above analysis and previous studies have shown the crucial role of the TIO SST anomaly to the anomalous WNPAC, it is still not clear how the sensitivity of the WNPAC to TIO SST anomaly will change. To investigate the atmospheric circulation anomaly over the WNP associated with a one-unit SST anomaly over the TIO, regressed anomalies of H850, $\zeta 850$, and vertical velocities at $500 \mathrm{hPa}(\omega 500)$ in JJA onto the TIO-SST index in JJA are shown in Fig. 4, where the TIO-SST index is defined as the regionalaveraged SST anomaly over $15^{\circ} \mathrm{S}-15^{\circ} \mathrm{N}, 50^{\circ}-110^{\circ} \mathrm{E}$. The anomaly patterns in Fig. 4 are generally the same as those in Fig. 3, with an anomalous anticyclone over the WNP and an anomalous cyclone over midlatitudes in the North Pacific associated with warm SSTA over TIO, demonstrating that TIO SSTAs in summer may explain a substantial fraction of a WNPAC anomaly in response to ENSO. An anomalous WNPAC is featured by positive $\mathrm{H} 850$ anomalies, negative $\zeta 850$ anomalies and positive $\omega 500$ anomalies (Figs. 4a,d,g). In 21C, locations of the anomalous WNPAC and the anomalous cyclone over midlatitudes in the North Pacific remain generally unchanged (Figs. 4b,e,h). The difference in the regression coefficient over the WNP between $21 \mathrm{C}$ and 20C (Figs. 4c,f,i) is generally opposite to those in 20C for every variable (i.e., H850, $\zeta 850, \omega 500$, and wind at $850 \mathrm{hPa}$ ), suggesting a weakened sensitivity of the WNPAC to TIO SST anomaly. Over the TIO, positive SST anomalies are associated with local ascending motion anomalies in both $20 \mathrm{C}$ and $21 \mathrm{C}$, suggesting the active forcing of the SST anomaly on the atmosphere. But the sensitivity of the anomalous $\omega 500$ values over TIO to local SST anomalies is much weaker in $21 \mathrm{C}$ than that in $20 \mathrm{C}$ (Fig. 4i), consistent with P. Huang et al. (2017).

To quantitatively evaluate the sensitivity of the WNPAC to tropical SST anomalies and intermodel uncertainties, we define a WNPAC index as regionalaveraged $\zeta 850$ over $10^{\circ}-30^{\circ} \mathrm{N}, 110^{\circ}-160^{\circ} \mathrm{E}$ (i.e., the box in Fig. 3d) multiplied by -1 , as in a previous study (He and Zhou 2014). The anomalies in the WNPAC index regressed onto the DJF Niño-3.4 index and the JJA 

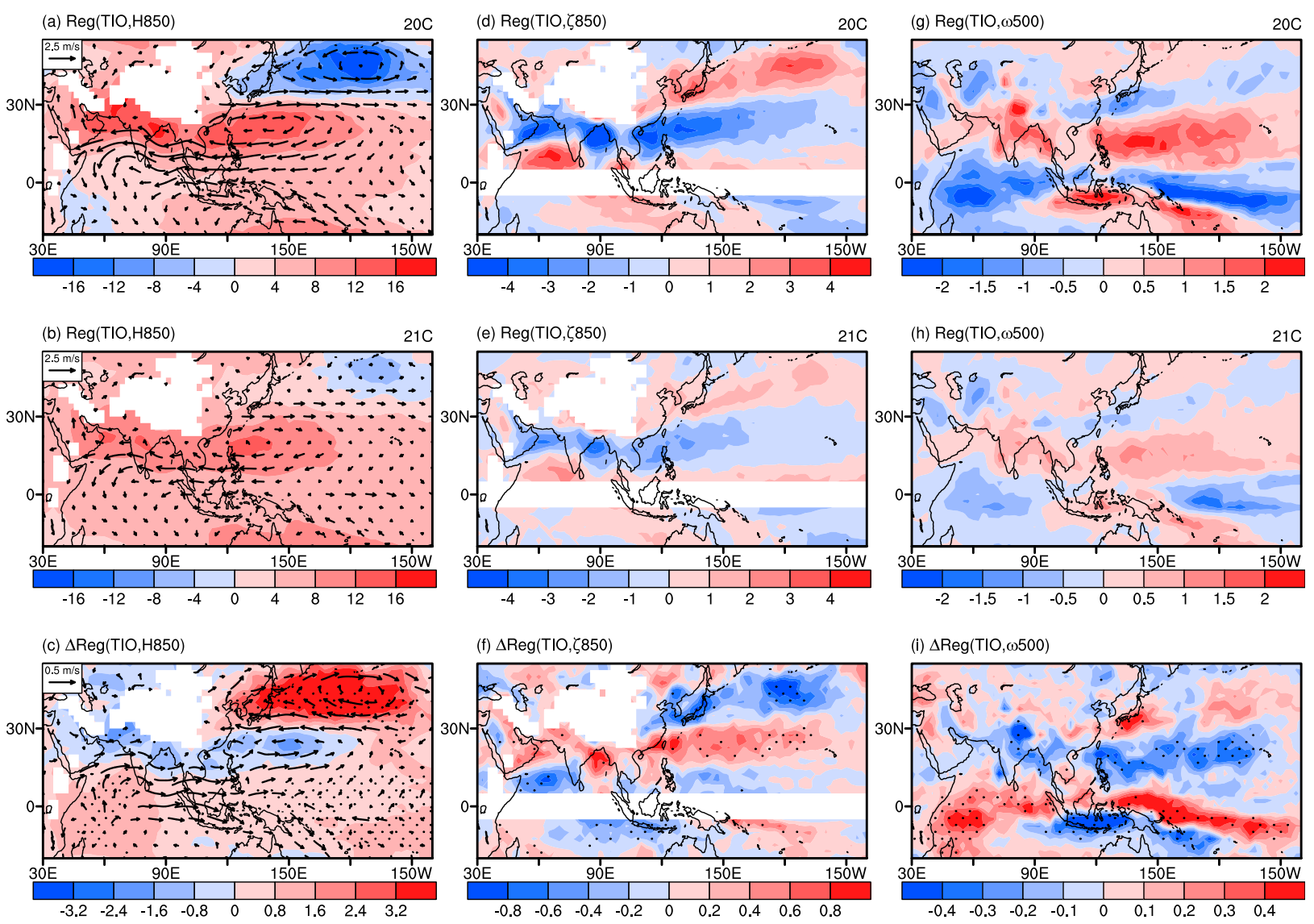

FIG. 4. As in Fig. 3, but for the regressed anomalies of (a)-(c) geopotential height and wind at $850 \mathrm{hPa}^{\left(g p m ~ \mathrm{~K}^{-1}\right.}$ and m s $\mathrm{K}^{-1}$, respectively), (d)-(f) relative vorticity at $850 \mathrm{hPa}\left(10^{-6} \mathrm{~s}^{-1} \mathrm{~K}^{-1}\right)$, and (g)-(l) vertical velocity at $500 \mathrm{hPa}\left(10^{-4} \mathrm{~Pa} \mathrm{~s}^{-1} \mathrm{~K}^{-1}\right)$ onto the JJA TIO-SST index.

TIO-SST index for the $20 \mathrm{C}$ in the historical experiment are shown in Fig. 5a. The positive regression slopes of the WNPAC index onto the DJF Niño-3.4 index and the JJA TIO-SST index are evident in most of the individual models and the MMM, suggesting an anomalous anticyclone (cyclone) in the decaying summer of an El Niño (La Niña) event that is accompanied by warm (cold) SST anomalies over the TIO. Based on the MMM, the sensitivity of the WNPAC index in summer to the DJF Niño-3.4 index in the $20 \mathrm{C}$ is $0.39 \times$ $10^{-6} \mathrm{~s}^{-1} \mathrm{~K}^{-1}$, and the sensitivity of the WNPAC index to the TIO-SST index is $1.49 \times 10^{-6} \mathrm{~s}^{-1} \mathrm{~K}^{-1}$ in the $20 \mathrm{C}$.

A few models show very weak or reversed relations in the WNPAC with ENSO or TIO SSTAs, and there are two possible causes. First, there are biases in these models (Hu et al. 2014; Song and Zhou 2014b; Wu and Zhou 2016). Second, the historical experiment is not designed to capture the observed phase of the internal variability, but the time scope selected for the analysis coincides with a period when the WNPAC-ENSO relationship is weak because of the internal climate variability of the model (Song and Zhou 2015). Observational studies showed that the WNPAC is strongly correlated with ENSO and TIO SSTAs in several decades, but these correlations are near zero or with reversed sign in other decades (Huang et al. 2010; Chowdary et al. 2012; $\mathrm{He}$ and Zhou 2015; Song and Zhou 2015; Gu et al. 2017). Given the observational uncertainty, we divide the observational data spanning 1948-2017 (a total of 70 years) into 30 segments, each with a length of 40 years (i.e., 1948-87, 1949-88, and 1978-2017). The regressed WNPAC index onto the Niño-3.4 index and the TIO-SST index is obtained for each segment, and a total of 30 pairs of regression coefficients are obtained to estimate the uncertainty range in the observation. In the observation, the regression coefficients of the WNPAC index onto the Niño-3.4 index range from $0.33 \times 10^{-6}$ to $0.61 \times 10^{-6} \mathrm{~s}^{-1} \mathrm{~K}^{-1}$, and the regression coefficients of the WNPAC index onto the TIO-SST index range from $1.21 \times 10^{-6}$ to $3.06 \times 10^{-6} \mathrm{~s}^{-1} \mathrm{~K}^{-1}$ (shown as the red box in Fig. 5a). The MMM and four individual models fall within the range of observational 
(a) $20 \mathrm{C}$

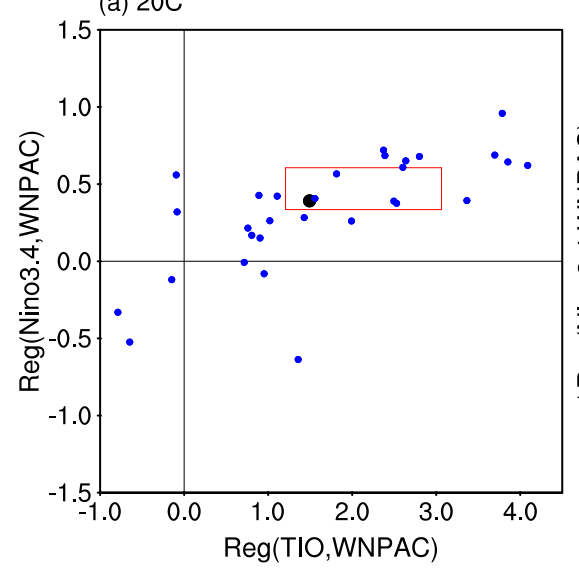

(b) $\Delta$ Reg

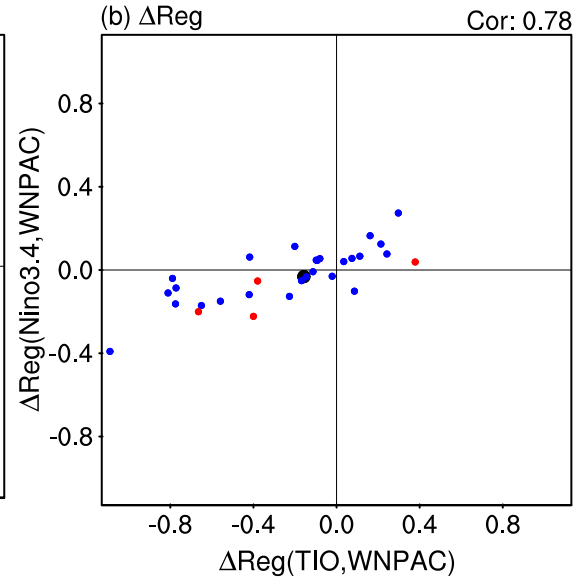

FIG. 5. The regressed anomalies of the WNPAC index for the individual models $\left(10^{-6} \mathrm{~s}^{-1} \mathrm{~K}^{-1}\right)$. (a) The regressed anomaly of the WNPAC index onto the DJF Niño-3.4 index ( $y$ axis) as a function of the regressed anomaly of the WNPAC index onto the JJA TIO-SST index ( $x$ axis) for 20C. The black dot indicates the MMM, and the blue dots indicate the individual models. The red box shows the uncertainty range of the regression coefficient from the observation data. (b) The projected changes of the regressed anomalies as the difference between $21 \mathrm{C}$ and $20 \mathrm{C}$ scaled by tropical-mean warming. The black dot indicates the MMM, the red dots indicate the high-skill models, and the blue dots indicate the other models.

uncertainty (i.e., within the box in Fig. 5a). These four models are CESM1-CAM5, FGOALS-g2, GISS-E2-R, and MIROC-ESM-CHEM, and they are used as "high skill" models. The selection of these four models is consistent with an independent study that measured model skills with other metrics regarding the East Asian summer monsoon (Song and Zhou 2014b).

Changes in the sensitivity of WNPAC index to Niño3.4 index and TIO-SST index for individual models are shown in Fig. 5b. The weakened sensitivity of the summertime WNPAC to the Niño-3.4 index in the previous winter is evidenced by 17 models, while the other 13 models project enhanced sensitivity. Although there are substantial intermodel uncertainties regarding the weakened sensitivity of the WNPAC to the DJF Niño3.4 index, the weakened sensitivity of the WNPAC to the TIO SSTs is agreed upon in 21 of the 30 models (i.e., $70 \%$ intermodel consistency) (Fig. 5b). According to the MMM, the anomalous WNPAC index regressed onto the TIO-SST index is weakened by $15.9 \%$ per $1 \mathrm{~K}$ of warming. For the four high-skill models (the red dots in Fig. 5b), only one of them shows an enhanced sensitivity of the WNPAC to the Niño-3.4 index and the TIO-SST index; the other three models agree in sign with the MMM. Therefore, it is a robust phenomenon that oneunit SSTA in TIO could stimulate a weaker anomalous WNPAC under a warmer climate. The intermodel correlation between the changes in regression slope of the WNPAC on the Niño-3.4 index and the changes in regression slope of the WNPAC on the TIO-SST index in
Fig. $5 \mathrm{~b}$ is 0.78 , suggesting that the weakened sensitivity of the WNPAC to the TIO SSTA forcing plays an essential role in the weakening of the WNPAC anomaly during an El Niño-decaying summer.

The WNPAC-SSTA relationship from the observations is also subject to uncertainty because of the quality of the reanalysis data (e.g., Kumar and $\mathrm{Hu} 2012$ ) or the sampling variability (Cash et al. 2017). If we divide the 70 years of observation into 40 segments, with each of them containing 30 consecutive years, the regression slope of the WNPAC index onto the Niño-3.4 index ranges from $0.15 \times 10^{-6}$ to $0.74 \times 10^{-6} \mathrm{~s}^{-1} \mathrm{~K}^{-1}$, and the regression slope of the WNPAC index onto the TIOSST index ranges from $-0.30 \times 10^{-6}$ to $3.55 \times$ $10^{-6} \mathrm{~s}^{-1} \mathrm{~K}^{-1}$ in the observation. Previous studies have also suggested that there are great decadal oscillations in the relationship between the WNPAC and ENSO or TIO SSTs (Huang et al. 2010; Chowdary et al. 2012; He and Zhou 2015; Song and Zhou 2015; Gu et al. 2017), and the correlation coefficients are slightly negative around the 1960s from the observations (Huang et al. 2010; Song and Zhou 2015), which is similar to some of the results from the "low skill" models. Therefore, it may not be reasonable to exclude models that have a weak WNPAC-ENSO relationship, and the results obtained from a small group of models may be more strongly biased because of internal variability (Deser et al. 2012). Since the ensemble median is not sensitive to the outlier models (Gleckler et al. 2008), and it is qualitatively consistent with the high-skill models, the 
ensemble median of the 30 models is reasonable and will be further used in the following discussion.

Internal variability also explains the discrepancy between our results and Zheng et al. (2011). Zheng et al. (2011) suggested a strengthened sensitivity of WNPAC to TIO SSTA, based on the outputs of GFDL_CM2.1. The projected change by a single model may not be caused by the GHG-forced climate response, as the impact of internal variability may overwhelm the GHGforced response. Our result about the weakened WNPAC anomaly is consistent with Jiang et al. (2018), which used a large ensemble of models. Although Jiang et al. (2018) attributed the weakened anomalous WNPAC to the weakened SSTA gradient between TIO and WNP, it is obvious from Fig. 6 of Jiang et al. (2018) that the decreased TIO-WNP SSTA gradient is dominated by the SSTA over WNP, whereas the contribution from TIO is negligible. However, our results and Fig. 4c of Jiang et al. (2018) consistently show that there is a positive SSTA over WNP during the El Niño-decaying summer in the models. According to previous studies (e.g., Sui et al. 2007; Wu et al. 2010), the warm SSTA over WNP in summer, if it forces the atmosphere, stimulates an anomalous cyclone over WNP. Indeed, the JJA mean SSTA over WNP during the El Niñodecaying summer is forced by the atmosphere rather than forcing the atmosphere at the interannual time scale (Wu et al. 2009b), and the projected changes of the WNPAC anomaly interacts with the SSTA over WNP under global warming (Jiang et al. 2018), which makes it difficult to distinguish the cause and effect between the changes of anomalous WNPAC and the SSTA over WNP. Because the above evidence has shown that TIO plays an essential role in the weakened WNPAC anomaly, the mechanism for the weakened impact of TIO SSTA on the WNPAC will be investigated in detail.

\section{Mechanism for the weakened WNPAC anomaly}

Because atmospheric circulation anomalies in the tropics are driven by diabatic heating, with a dominant contribution deriving from latent heating associated with precipitation, the regressed precipitation anomalies onto the TIO-SST index and its changes are shown in Figs. 6a-c. It is clear that warm SSTAs over the TIO are indeed associated with local positive precipitation anomalies, with a positive precipitation anomaly over the equatorial Pacific and negative precipitation anomalies over its northern and southern flanks off the equator. However, the positive precipitation anomaly over the equatorial Pacific does not favor an anomalous anticyclone over the WNP because it stimulates a cyclonic Rossby wave response to the northwest (Wang et al. 2013;
Z. Chen et al. 2016). The positive rainfall and associated latent heating anomaly over the TIO are essential external forcing for the formation of a WNPAC, whereas the negative precipitation anomaly over the WNP is coupled with anomalous WNPAC (Xie et al. 2009; Jin et al. 2013; Xiang et al. 2013). For both the 20C and 21C epochs, positive SST anomalies over the TIO are associated with positive precipitation anomalies over the TIO basin, but the positive precipitation anomaly over the TIO is weaker in $21 \mathrm{C}$ than in $20 \mathrm{C}$ (Fig. 6b). The positive precipitation anomaly averaged within $15^{\circ} \mathrm{S}-15^{\circ} \mathrm{N}, 50^{\circ}-$ $110^{\circ} \mathrm{E}$ is weakened by $14.8 \%$ per $1 \mathrm{~K}$ of warming. The weakened sensitivity of TIO precipitation to local SSTA forcing is a robust phenomenon evidenced by more than $70 \%$ of the models over a large fraction of TIO, especially over the western TIO (Fig. 6c).

Following Yanai and Tomita (1998), the threedimensional diabatic heating field is calculated, and the diabatic heating anomaly regressed onto the TIOSST index and its change are shown in Figs. $6 \mathrm{~d}-\mathrm{i}$ at $500 \mathrm{hPa}$ and in terms of the latitude-height profile averaged over $50^{\circ}-110^{\circ} \mathrm{E}$. The diabatic heating anomaly becomes less sensitive to the underlying SST anomaly over the TIO in a warmer climate (Figs. 6d-i), as evidenced by the weaker magnitude of the anomalies in $21 \mathrm{C}$ than in $20 \mathrm{C}$. The spatial patterns for the diabatic heating anomaly and its change resemble those for precipitation, and the vertical profiles for the diabatic heating anomalies are characterized by a maximum in the midtroposphere at approximately $500 \mathrm{hPa}$ (Figs. $6 \mathrm{~g}-\mathrm{i})$, suggesting a dominant contribution from latent heating associated with precipitation to the total diabatic heating. In summary, the diabatic heating associated with the precipitation anomaly over the TIO forced by local SSTA over TIO is weaker in a warmer climate. The effect of the change in the diabatic heating anomaly over TIO during the El Niñodecaying summer on the anomalous WNPAC will be investigated in section $4 \mathrm{a}$, and the possible mechanism for the weakened impact of SSTA over TIO on the local precipitation anomaly will be investigated in section $4 \mathrm{~b}$.

\section{a. Effect of the weakened TIO heating anomaly on the WNPAC anomaly}

To investigate whether the weakened diabatic heating anomaly over the TIO is responsible for the weakened WNPAC anomaly, idealized numerical experiments are performed with a linear baroclinic model (LBM) developed by Watanabe and Kimoto (2000). The LBM is linearized at the JJA mean state derived from the NCEP-NCAR reanalysis, and two experiments are performed. One is forced by the regressed three-dimensional 
(a) $\operatorname{Reg}(\mathrm{TIO}, \mathrm{Pr})$

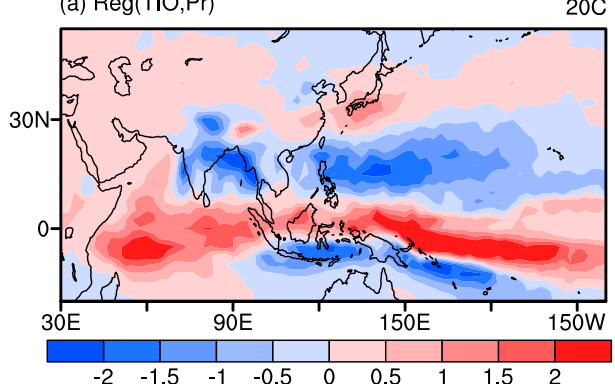

(b) $\operatorname{Reg}(\mathrm{TIO}, \mathrm{Pr})$

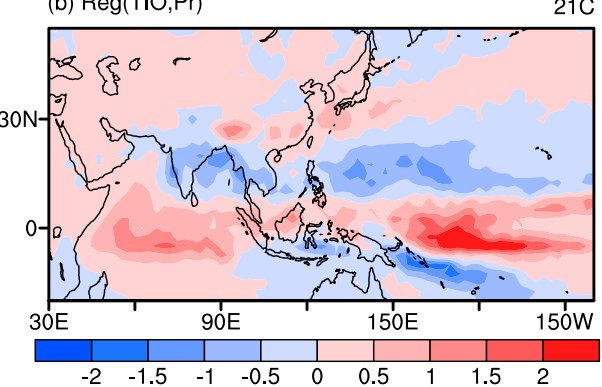

(c) $\Delta \operatorname{Reg}(\mathrm{TIO}, \mathrm{Pr})$

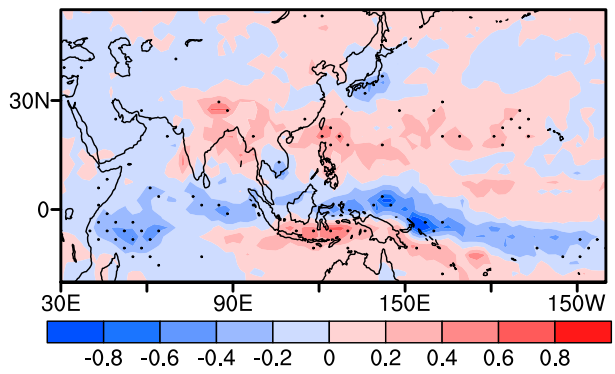

(d) $\operatorname{Reg}(T I O, Q 500)$

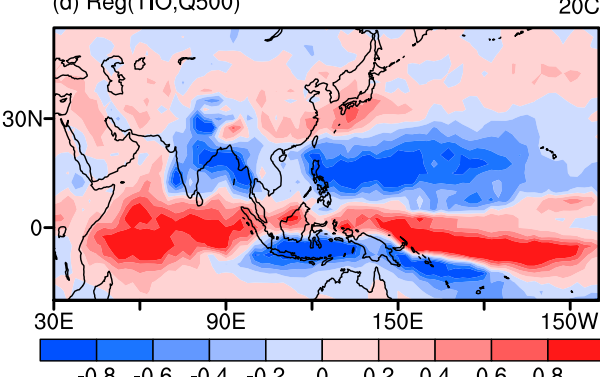

$20 \mathrm{C}$

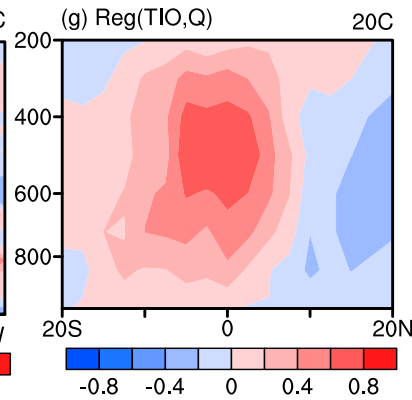

(e) $\operatorname{Reg}(\mathrm{TIO}, \mathrm{Q} 500)$
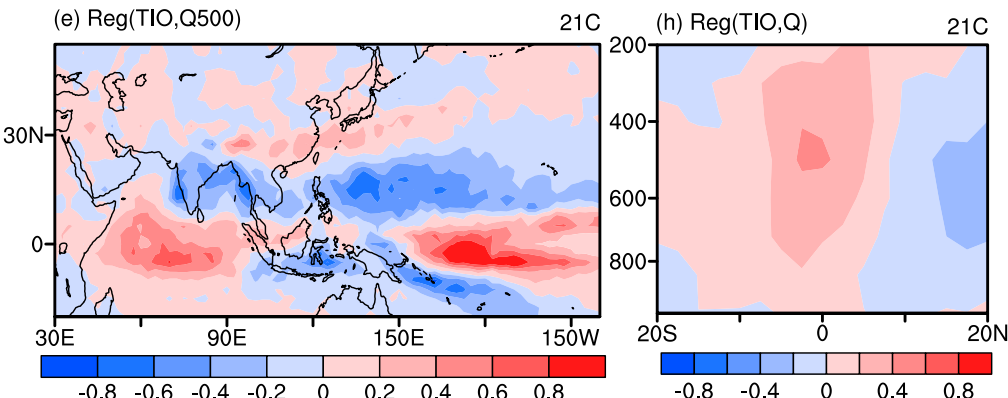

(f) $\Delta \operatorname{Reg}(\mathrm{TIO}, \mathrm{Q} 500)$
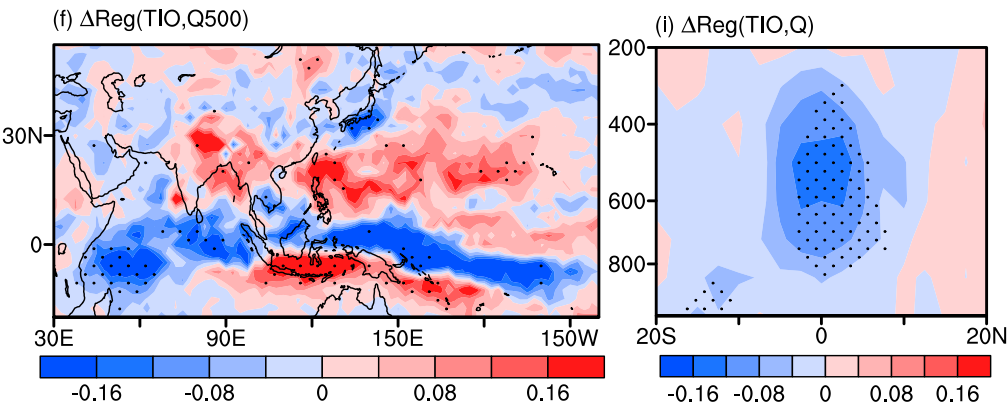

FIG. 6. Regressed precipitation and diabatic heating anomalies onto the TIO-SST index and their changes. (a)-(c) Precipitation anomalies regressed onto the JJA TIO-SST index $\left(\mathrm{mm} \mathrm{day}^{-1} \mathrm{~K}^{-1}\right)$ for (a) $20 \mathrm{C}$, (b) $21 \mathrm{C}$, and (c) the difference between $21 \mathrm{C}$ and $20 \mathrm{C}$ scaled by tropical-mean warming. (d)-(f) As in (a)-(c), but for the regressed anomalies of diabatic heating at $500 \mathrm{hPa}\left(\mathrm{K} \mathrm{day}^{-1} \mathrm{~K}^{-1}\right)$. (g)-(i) As in (a)-(c), but for the vertical profile of diabatic heating over TIO (averaged within $50^{\circ}-110^{\circ} \mathrm{E}$ ).

positive diabatic heating anomaly over the TIO $\left(15^{\circ} \mathrm{S}-\right.$ $15^{\circ} \mathrm{N}, 50^{\circ}-110^{\circ} \mathrm{E}$ ) for $20 \mathrm{C}$, and the other is forced by the regressed positive diabatic heating anomaly in $21 \mathrm{C}$ (see Fig. 6). For each experiment, the LBM is consecutively integrated for 50 days and the average for the last 20 days is examined. The responses of the relative vorticity and the wind at $850 \mathrm{hPa}$ to the diabatic heating anomaly are shown in Fig. 7.

Forced by the positive heating anomaly over the TIO, the LBM has reproduced the anomalous anticyclone over the WNP in terms of meridional wind shear and negative $\zeta 850$ (Figs. 7a,b). The magnitude of the $\zeta 850$ anomaly over the WNP within $10^{\circ}-30^{\circ} \mathrm{N}$ in the LBM is comparable with those in the coupled model simulations, although the anomalous easterly wind along $30^{\circ} \mathrm{N}$ over the WNP is weaker because of the absence of local convection-circulation feedback over the WNP
(Xie et al. 2009). Based on the LBM simulation, the WNPAC anomaly forced by the TIO heating anomaly in $21 \mathrm{C}$ is substantially weaker than that in $20 \mathrm{C}$. If the WNPAC intensity is measured by averaging the $\zeta 850$ within $10^{\circ}-30^{\circ} \mathrm{N}, 110^{\circ}-160^{\circ} \mathrm{E}$, the LBM-simulated intensity of the anomalous WNPAC is weakened by $19.2 \%$ per $1 \mathrm{~K}$ of warming, which is comparable to the coupled model projection. The substantially weakened meridional PJ/EAP pattern in the CMIP5 models is not captured by the LBM, because of the lack of the feedback of circulation on local convection over WNP (Xie et al. 2009). But the LBM experiments confirm that the weakened heating anomaly over the TIO is the primary external forcing that is responsible for the weakened WNPAC anomaly.

The weakened effect of the heating anomaly over TIO on the atmosphere can also be identified in the CMIP5 
(a) $\zeta 850$

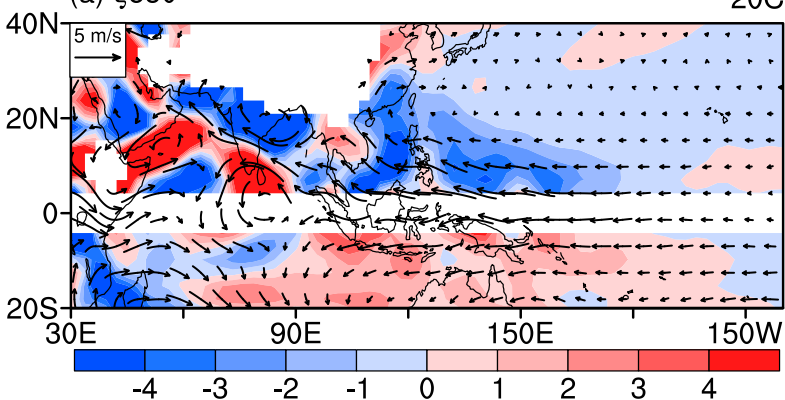

(b) $\zeta 850$

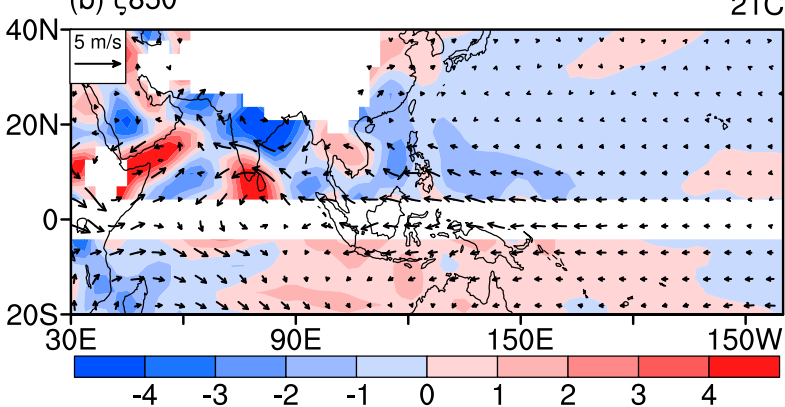

(c) $\Delta \zeta 850$

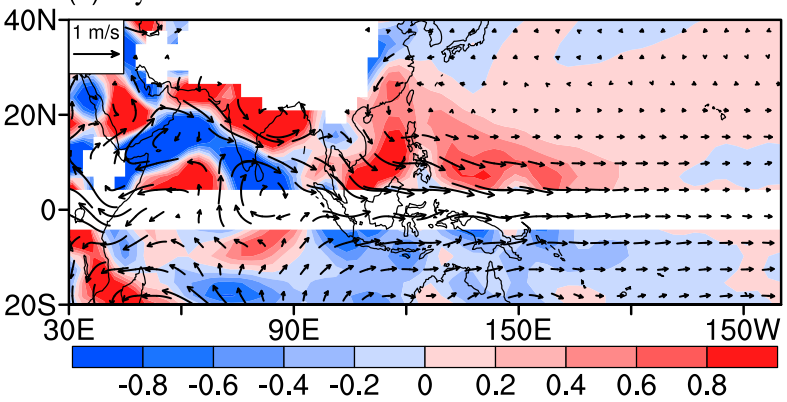

FIG. 7. The responses of relative vorticity $\left(10^{-6} \mathrm{~s}^{-1} \mathrm{~K}^{-1}\right)$ and wind at $850 \mathrm{hPa}$ in the LBM to the prescribed diabatic heating anomalies. The prescribed heating anomalies are based on the regressed anomalies of three-dimensional diabatic heating over the TIO $\left(15^{\circ} \mathrm{S}-15^{\circ} \mathrm{N}, 50^{\circ}-110^{\circ} \mathrm{E}\right)$ onto the TIO-SST index, which are shown in Fig. 6, for (a) 20C and (b) 21C. (c) The difference in the LBM responses between the $21 \mathrm{C}$ and $20 \mathrm{C}$, which is scaled by tropical-mean warming.

models. The TT (850-200-hPa-averaged tropospheric temperature) anomaly is usually adopted to measure the intensity of the warm Kelvin wave stimulated by TIO heating (e.g., Xie et al. 2009; Chowdary et al. 2012; Hu et al. 2014). But the warm TT anomaly over the entire tropics during El Niño is enhanced in a warmer climate, as implied by previous studies (Hu et al. 2014; Tao et al. 2015) and will be shown in section 4b. By removing the contemporary tropical-mean TT, the residual component (TT*) can be used to measure the Kelvin wave associated with TIO forcing, and the $\mathrm{TT}^{*}$ anomaly regressed onto the TIO-SST index in the CMIP5 models is shown in Fig. 8. The regressed TT* anomaly captures the wedgelike warm Kelvin wave emanating from the TIO caused by a positive heating anomaly over TIO, and a pair of cold anomalies over the subtropical WNP and around Australia caused by the suppressed diabatic heating (Figs. 8a,b). The warm Kelvin wave emanating from the TIO, as measured by the TT* over the TIO, is substantially weaker in $21 \mathrm{C}$ than in $20 \mathrm{C}$ (Figs. 8b,c). The weakened latent heating anomaly over TIO as shown in Fig. 6 is responsible for the weakened warm TT* anomaly over TIO, and the weakened negative latent heating anomalies over WNP and its counterpart in the Southern Hemisphere are responsible for the weakened local cold TT* anomalies. In all, the warm Kelvin wave emanating from TIO is weakened as a result of the weakened positive heating anomaly over TIO, which explains the weakened sensitivity of WNPAC to TIO forcing in a warmer climate (Wu et al. 2009a; Xie et al. 2009).

\section{b. Causes for the weakened sensitivity of TIO precipitation anomaly to local SSTA}

Based on the regressed TT anomaly onto the DJF Niño-3.4 index, the free troposphere of the tropics is warmer than normal during the El Niño-decaying phase, for both $20 \mathrm{C}$ and $21 \mathrm{C}$ (Fig. 9). In summer, the warm TT anomaly is rather uniform through the tropics. In a warmer climate, the warm TT anomaly is enhanced from spring to summer during the El Niño-decaying phase (Figs. 9c,f). Previous studies suggested that the enhanced warm TT anomaly results from the enhanced moist adiabatic adjustment in a moister atmosphere $(\mathrm{Hu}$ et al. 2014; Tao et al. 2015). The MMM of the tropicalaveraged TT anomaly in JJA averaged between $25^{\circ} \mathrm{S}$ and $25^{\circ} \mathrm{N}$ regressed onto the DJF Niño-3.4 index is $0.55 \mathrm{~K} \mathrm{~K}^{-1}$ for $20 \mathrm{C}$ and $0.67 \mathrm{~K} \mathrm{~K}^{-1}$ for $21 \mathrm{C}$ (Fig. 10a). The magnitude of its increase is $0.06 \mathrm{~K}$ per $1 \mathrm{~K}$ of tropical-mean surface warming, which is robust among the models (Fig. 10b).

In contrast to the increased warm TT anomaly during the El Niño-decaying summer, the increase of TIO SSTA in the El Niño-decaying summer is weak and uncertain among the models (Figs. 9, 10), although the total amplitude of interannual SST variability measured by the standard deviation is increased over TIO (Fig. 1). The magnitude of the increase in TIO SSTA in the El Niño-decaying summer is less than $0.01 \mathrm{~K}$ per $1 \mathrm{~K}$ of tropical-mean surface warming, and is not agreed by more than $70 \%$ of the individual models (Fig. 10b). In contrast, the tropical-mean warm SSTA is significantly enhanced (Fig. 10), because of the adjustment of SSTA to the enhanced TT anomaly (Hu et al. 2014; Tao et al. 
(a) $\operatorname{Reg}\left(\mathrm{TIO}^{\mathrm{T}} \mathrm{TT}^{*}\right)$

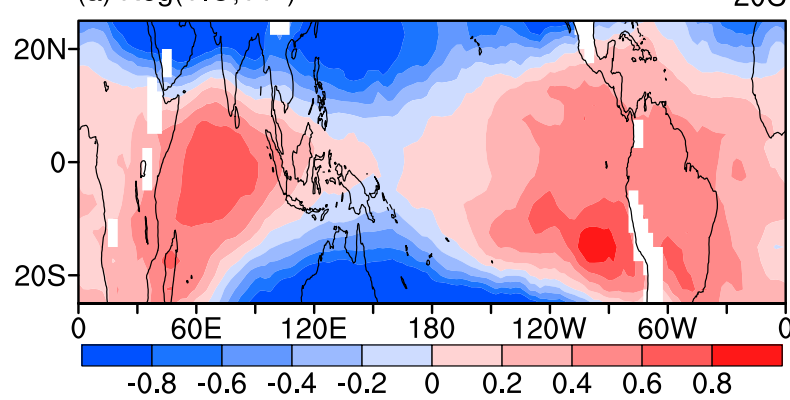

(b) $\operatorname{Reg}\left(\mathrm{TIO}^{\mathrm{T}} \mathrm{TT}^{*}\right)$

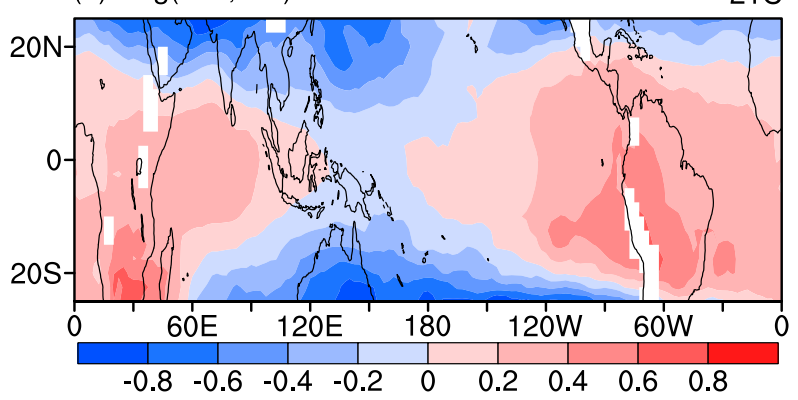

(c) $\Delta \operatorname{Reg}\left(\mathrm{T} \mid \mathrm{O}, \mathrm{TT}^{*}\right)$

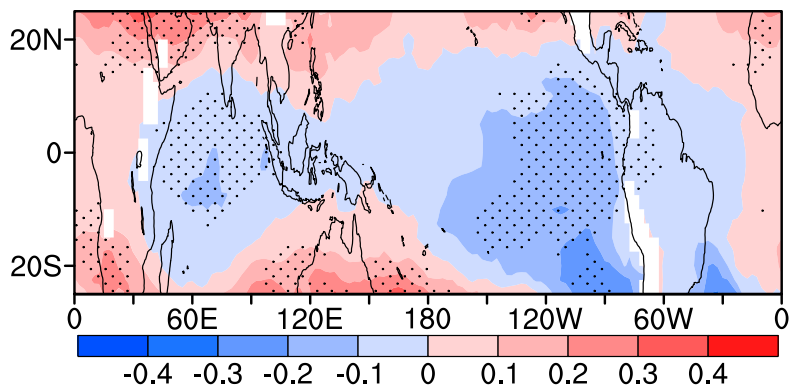

FIG. 8. Regressed anomaly of TT* in JJA onto the TIO-SST index and its change, where $\mathrm{TT}^{*}$ is the departure of TT from tropical-mean TT. (a) $20 \mathrm{C}$ and (b) $21 \mathrm{C}$, and (c) is the change in the regression coefficients per $1 \mathrm{~K}$ of tropical-mean surface warming.

2015; Jiang et al. 2018). The deviation of positive SSTA over TIO from the tropical mean (denoted as TIOSST*) becomes slightly weaker in a warmer climate (Fig. 10), but is still not agreed upon by $70 \%$ of the models. In a warming climate, the tropical convection follows relative distribution of tropical SST instead of the absolute magnitude of SST, and tropical convection tends to occur where the SST is warmer than the tropical-mean SST (Johnson and Xie 2010). Since the change in TIO SSTA during the El Niño-decaying summer is weak and uncertain regardless of whether the tropical-mean SST is removed but the increase of warm TT anomaly in the free troposphere is robust (Fig. 10b), the boundary layer over TIO becomes more stable and is unfavorable for the positive convective rainfall anomaly over TIO. This acts to weaken the impact of TIO SSTA on the local precipitation anomaly in a warmer climate, and will further stimulate a weakened atmospheric circulation anomaly.

The enhanced tropical TT anomaly in a moister atmosphere favors enhanced warm SSTA throughout the tropics including TIO (Hu et al. 2014; Tao et al. 2015), and the weak and insignificant change of TIO SSTA may possibly result from the opposing effect of other processes. During the El Niño-decaying summer, the wind anomaly over TIO opposes the mean-state summer monsoon circulation and helps to maintain the warm SSTA via wind-evaporation-SST feedback within TIO (Du et al. 2009). As the wind anomaly over TIO is weakened associated with the weakened WNPAC anomaly in a warmer climate, its cooling effect on the TIO SSTA offsets the effect of the enhanced warm TT anomaly (Jiang et al. 2018).

To verify the above mechanism for weakened impact of TIO SSTA on local precipitation in a warmer climate, numerical experiments are performed by using CAM5. Two control experiments are performed under different mean-state SSTs. One control experiment named as CTL_PD is forced by the climatological annual cycle of present-day SST released by Hurrell et al. (2008), and the other control experiment named as CTL_PD $+1 \mathrm{~K}$ is performed by uniformly adding $1 \mathrm{~K}$ to the global SST as used in the CTL_PD experiment. To examine the impact of TIO SSTA in the El Niño-decaying summer, the warm SSTA over TIO $\left(15^{\circ} \mathrm{S}-15^{\circ} \mathrm{N}, 50^{\circ}-110^{\circ} \mathrm{E}\right)$ from June to August and the warm SSTA over equatorial Pacific $\left(10^{\circ} \mathrm{S}-10^{\circ} \mathrm{N}, 160^{\circ} \mathrm{E}-80^{\circ} \mathrm{W}\right)$ from March to August are added to the SSTs in CTL_PD and CTL_PD+1K experiments, respectively, to perform two sensitivity experiments named as SEN_PD and SEN_PD+1K. The SSTAs over TIO and equatorial Pacific are obtained from the MMM of SSTA regressed onto DJF Niño-3.4 index in 20C (see Fig. S1 in the online supplemental material for the prescribed SSTA in each month), and a comparison among the prescribed SST for the four experiments are listed in Table 1. All of these four experiments are consecutively run for 20 years, and the last 18 years are adopted as 18 samples.

The difference between SEN_PD and CTL_PD experiments represents the atmospheric anomalies associated with warm TIO SSTA during decaying El Niño in present-day mean state (PD condition), whereas the difference between SEN_PD+1K and CTL_PD+1K experiments represents those in an idealized global warming condition with a uniform warming of meanstate SST by $1 \mathrm{~K}(\mathrm{PD}+1 \mathrm{~K}$ condition). In both $\mathrm{PD}$ and $\mathrm{PD}+1 \mathrm{~K}$ conditions, the tropical atmosphere is governed by warm TT anomaly in JJA (Figs. 11a,b), but the 

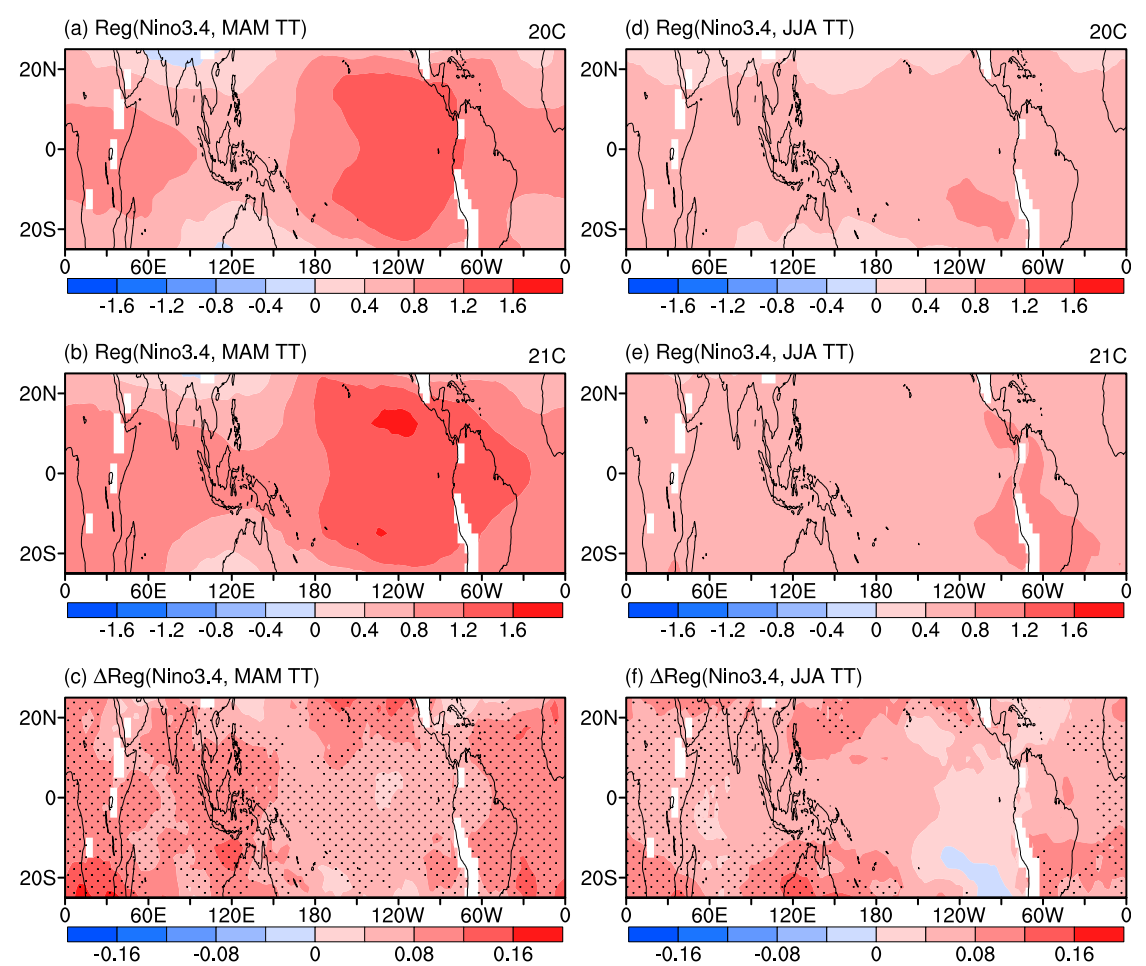

FIG. 9. The regressed anomalies of tropospheric temperature $\left(\mathrm{K} \mathrm{K}^{-1}\right)$ in (a)-(c) MAM and (b)-(d) JJA onto Niño-3.4 index in DJF and their changes. The regressed anomalies in (top) $20 \mathrm{C}$ and (middle) $21 \mathrm{C}$, and (bottom) the difference between $21 \mathrm{C}$ and $20 \mathrm{C}$ scaled by tropicalmean warming.

tropical-mean TT anomaly rises from $0.21 \mathrm{~K}$ in the PD condition to $0.30 \mathrm{~K}$ in the PD+1K condition (Fig. 12a). This enhancement is possibly due to the enhanced moist adiabatic adjustment caused by the increase of meanstate SST (Hu et al. 2014; Tao et al. 2015), since the SSTA forcing is the same for PD and PD $1 \mathrm{~K}$ conditions. Over the TIO, the positive precipitation anomaly is seen in both the PD and PD $+1 \mathrm{~K}$ conditions (Fig. 11c,d), but the regional-averaged precipitation anomaly over TIO drops from $0.29 \mathrm{~mm} \mathrm{day}^{-1}$ in the PD condition to $0.11 \mathrm{~mm} \mathrm{day}^{-1}$ in the PD+1K condition (Fig. 12b). The reduction in the TIO precipitation anomaly possibly results from the enhanced static stability of the atmospheric boundary layer associated with the enhanced warm TT anomaly above the unchanged TIO SSTA. As the positive precipitation over TIO is weakened, the anticyclone wind anomaly over WNP is also weakened in the $\mathrm{PD}+1 \mathrm{~K}$ condition (Figs. 11c,d). The above experiments support the mechanism for the weakened sensitivity of TIO precipitation anomaly to local SSTA in a warmer mean state, although the anomalies in CAM5 are not exactly the same in quantity as in the MMM of CMIP5 models.

Based on the above analyses and model experiments, the weakened sensitivity of TIO precipitation to local
SSTA is crucial for the weakened anomalous WNPAC during the El Niño-decaying summer. In a warmer climate, the warm TT anomaly in the free troposphere of the tropics during the El Niño-decaying phase is robustly enhanced because of enhanced moist adiabatic adjustment of the troposphere to the El Niño-related SSTA, even if the strength of El Niño is unchanged. The substantially enhanced warm TT anomaly in the free troposphere and the generally unchanged TIO SSTA results in a more stable boundary layer over TIO, which is unfavorable for the formation of the positive rainfall anomaly over TIO. As the precipitation anomaly over TIO is weakened, the associated latent heating anomaly is also weakened and a weaker Kelvin wave is stimulated from the TIO, which is crucial for the weakened WNPAC anomaly. Although Jiang et al. (2018) emphasized the impact from the projected change of SSTA (especially the SSTA over WNP), our results show that the anomalous WNPAC is substantially weakened because of mean-state warming even if the SSTA remains unchanged. Based on the evidence shown in our work, the weakened impact of TIO SSTA on the atmosphere results in a substantially weakened WNPAC anomaly during the El Niño-decaying summer under the 

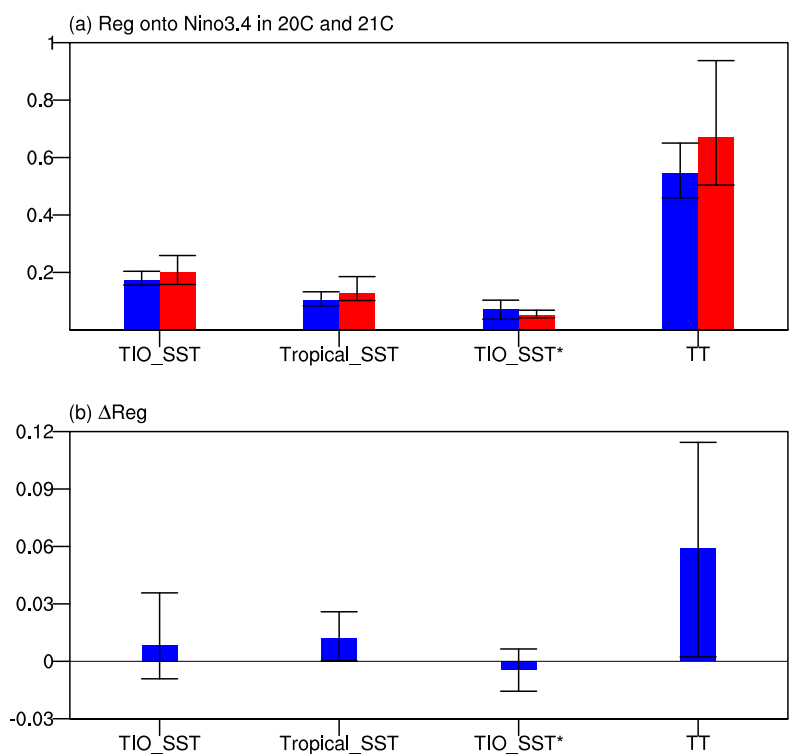

FIG. 10. (a) Regression coefficients of four indices in JJA onto Niño-3.4 index in DJF. These four indices are averaged SSTA over TIO (TIO-SST), tropical-mean SSTA (tropical-SST), departure of TIO-SST from tropical-mean SST (TIO-SST*), and tropical-mean tropospheric temperature (TT). The regression coefficients in 20C and $21 \mathrm{C}$ are indicated by blue and red bars, respectively. (b) The changes in the above regression coefficients per $1 \mathrm{~K}$ of tropical warming, with the range between the 30th and 70th percentiles among the individual models indicated by the thin black bar.

warming climate even without any changes in SSTA. The change in SSTA caused by air-sea interaction (Jiang et al. 2018) may also have a contribution to further weaken the anomalous WNPAC and the associated PJ/EAP teleconnection pattern.

\section{Conclusions and discussion}

The WNPAC is a major circulation system that affects the climate variability over the East Asia-west Pacific region. In this study, the response of the anomalous WNPAC during the El Niño-decaying summer to global warming is investigated based on a comparison between the RCP 8.5 and the historical experiments of 30 coupled models participated in the CMIP5. We investigated the cause for the change in the WNPAC anomaly by investigating the amplitude of SST anomalies and the sensitivity of the WNPAC to SST anomalies. Evidence suggests that the weakened impact of TIO SSTA on the WNPAC plays a crucial role for the weakened anomalous WNPAC during the El Niño-decaying summer, and the weakened impact of the TIO on the anomalous WNPAC originates from the mean-state warming rather than the changes in SSTA. The proposed mechanism based on CMIP5 models is further confirmed by numerical experiments based on LBM and CAM5. The major findings are summarized as follows:

1) Although the magnitude of SST variability of ENSO generally remains unchanged, the anomalous WNPAC during the El Niño-decaying summer is projected to be weaker in a warmer climate. Based on the multimodel median, the intensity of the anomalous WNPAC during the El Niño-decaying summer will be reduced by approximately $11.4 \%$ per $1 \mathrm{~K}$ of warming with an intermodel uncertainty. The tropical Indian Ocean plays an essential role in the response of the anomalous WNPAC to global warming, and the reduced sensitivity of the WNPAC to TIO SST anomaly explains the decrease in the intensity of the anomalous WNPAC during the El Niño-decaying summer. Even if the SSTA over TIO is unchanged, the intensity of the WNPAC anomaly induced by TIO SSTA will still be reduced by approximately $15.9 \%$ per $1 \mathrm{~K}$ of warming and is robust among the models, because of the weakened sensitivity of latent heating associated with precipitation anomaly over TIO to local SSTA.

2) In a warmer climate, robustly stronger warm TT anomaly is stimulated by El Niño-related SSTA, via enhanced moist adiabatic adjustment in a moister atmosphere. This uniformly enhanced warm TT anomaly in the entire tropical free troposphere is favorable for an enhanced warm SSTA over the entire tropical oceans. But the change in the warm SSTA over TIO in El Niño-decaying summer is weak and insignificant, because of the offsetting effect of the local air-sea interaction. The substantially enhanced warm TT anomaly in the free troposphere above the generally unchanged SSTA

TABLE 1. Experimental design based on CAM5.

\begin{tabular}{|c|c|c|}
\hline Expt & Mean-state SST & SST anomalies \\
\hline CON_PD & Present day & None \\
\hline CON_PD+1K & Present day $+1 \mathrm{~K}$ & None \\
\hline SEN_PD & Present day & $\begin{array}{l}\text { Regressed SSTA over the equatorial Pacific from March to August and over TIO from } \\
\text { June to August onto the DJF Niño-3.4 index }\end{array}$ \\
\hline SEN_PD+1K & Present day $+1 \mathrm{~K}$ & $\begin{array}{l}\text { Regressed SSTA over the equatorial Pacific from March to August and over TIO from } \\
\text { June to August onto the DJF Niño-3.4 index }\end{array}$ \\
\hline
\end{tabular}


(a) TT anomaly

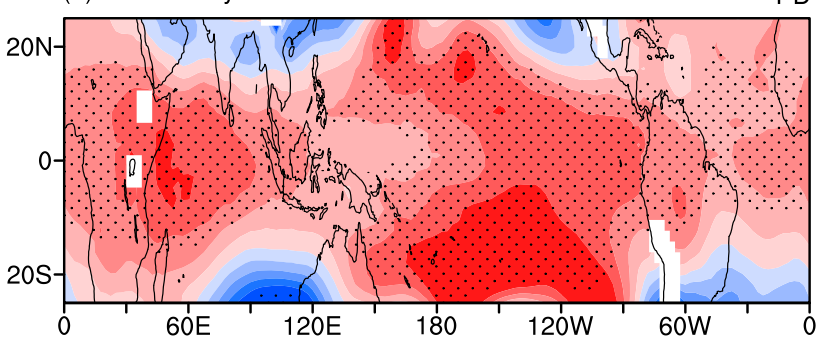

(b) TT anomaly

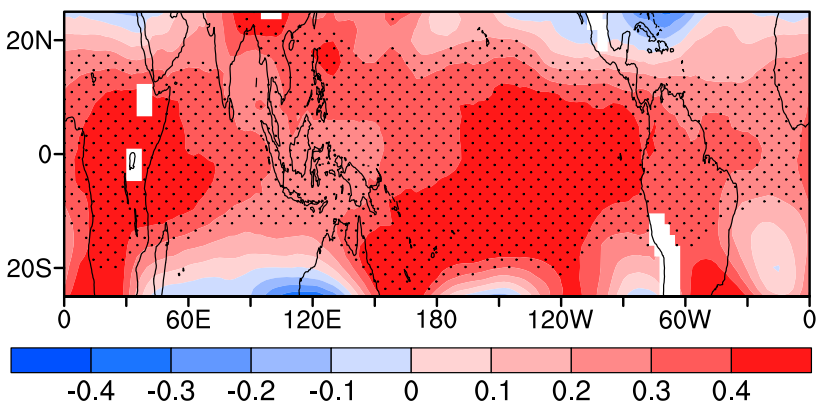

(c) Pr and wind anomaly

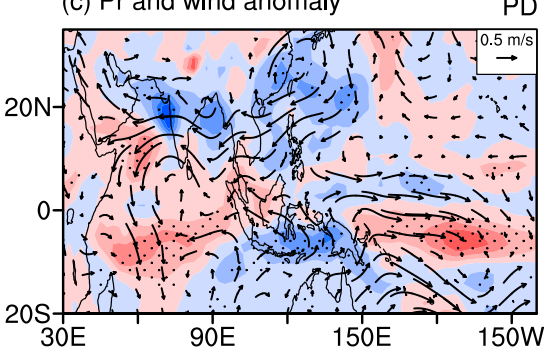

(d) Pr and wind anomaly

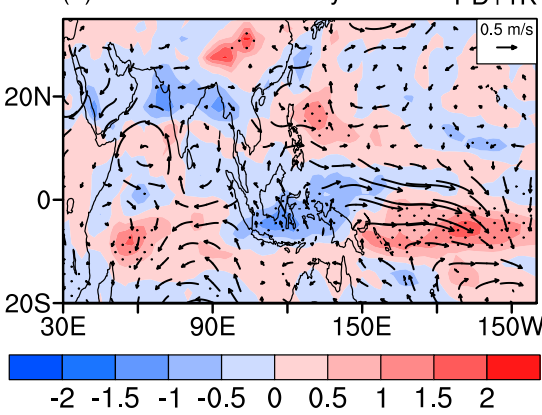

FIG. 11. (a) The difference of tropical TT in JJA between SEN_PD and CTL_PD experiments. (c) The difference of precipitation (shading) and 850-hPa wind anomalies (vectors) in JJA between SEN_PD and CTL_PD experiments. (b),(d) As in (a) and (c), but for the difference between SEN_PD+1K and CTL_PD+1K experiments. The differences significant at the $95 \%$ confidence level are stippled.

over TIO results in a more stable boundary layer, which is unfavorable for the development of convection over TIO during the El Niño-decaying summer. Therefore, the positive precipitation anomaly over TIO during the El Niño-decaying summer is weakened in the warmer climate, and the positive latent heating anomaly over TIO is weakened accordingly. The weakened heating anomaly over the TIO stimulates a weakened Kelvin wave emanating from TIO, which explains the weakened anomalous WNPAC.

The above analyses are based on the MMM of the climate models, and the mechanism is confirmed by the numerical experiments by CAM5 and LBM. In the observation and reanalysis data, the 40-yr runningregression coefficients of WNPAC index onto DJF Niño-3.4 index and JJA TIO-SST index have experienced a slight rise after the late 1970s (black lines in Fig. 13), and seem to decrease after the late 1990s. Previous studies also showed that the capacitor effect of the TIO is subject to substantial decadal oscillation, and suggested that its decadal change in the observational record originates from the internal variability of the climate system rather than global warming (Chowdary et al. 2012). As the phase of the internal variability is random among the models, the internal variability is suppressed in the MMM, and the signal associated with GHG-forced global warming is extracted in the MMM.
How strong is the internal variability in the individual models? By concatenating the time series of 1900-2005 in the historical experiment and 2006-99 in the RCP8.5 experiment into time series with a length of 200 years for the four "high skill" models, 40-yr running regression of the WNPAC index onto the DJF Niño-3.4 index and the JJA TIO-SST index are performed for each model. It is obvious that the anomalous (a) TT anom

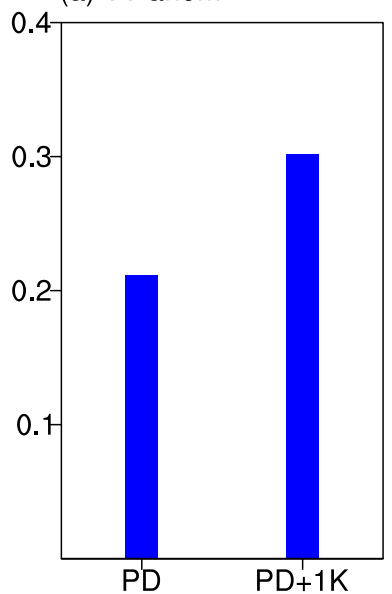

(b) TIO Pr anom

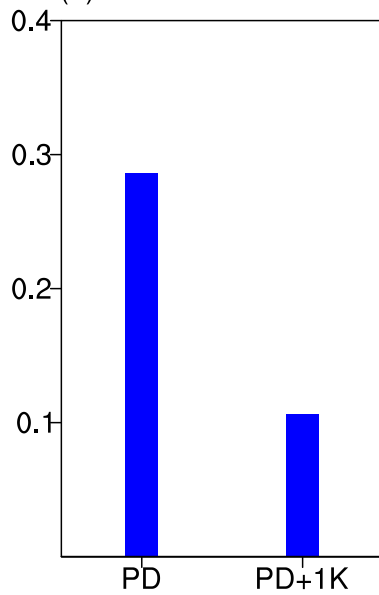

FIG. 12. (a) The difference of tropical $\left(25^{\circ} \mathrm{S}-25^{\circ} \mathrm{N}\right)$-mean TT between SEN_PD (SEN_PD+1K) and CTL_PD (CTL_PD+1K) experiments. (b) As in (a), but for the precipitation averaged over TIO $\left(15^{\circ} \mathrm{S}-15^{\circ} \mathrm{N}, 50^{\circ}-110^{\circ} \mathrm{E}\right)$. 

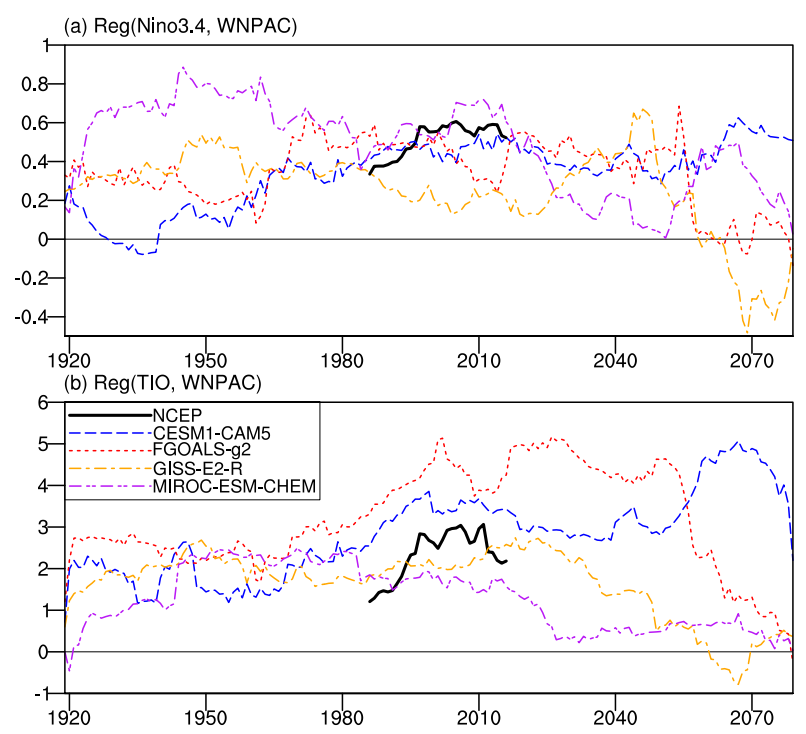

FIG. 13. The 40-yr running-regression coefficients of WNPAC index in JJA (a) onto DJF Niño-3.4 index and (b) onto JJA TIOSST index. The thick black line is based on the 1948-2017 period of reanalysis data, and the colored lines are based on the four highskill models including CESM1-CAM5 (blue), FGOALS-g2 (red), GISS-E2-R (orange), and MIROC-ESM-CHEM (purple).

WNPAC during the El Niño-decaying summer is also subject to strong decadal oscillation instead of monotonic weakening trend in every individual model (colored lines in Fig. 13). The decadal oscillation of the regressed WNPAC anomaly onto the DJF Niño-3.4 index ranges from about 0 to $0.8 \times 10^{-6} \mathrm{~s}^{-1} \mathrm{~K}^{-1}$ (Fig. 13a), which is much stronger than the projected change per $1 \mathrm{~K}$ of warming by the MMM $\left(-0.03 \times 10^{-6} \mathrm{~s}^{-1} \mathrm{~K}^{-1}\right.$, see Fig. 5b). The regressed anomaly of the anomalous WNPAC to the JJA TIO-SST index is generally in phase with those regressed onto the DJF Niño-3.4 index, suggesting the major contribution of the TIO capacitor effect to WNPAC during the El Niño-decaying summer.

Given that the internal variability can easily overwhelm the GHG-forced response, it is not surprising that the GHG-forced response is inconsistent with recent decadal change in the reanalysis data, which may be dominated by internal variability. As the internal variability is so strong but its phase is stochastic in coupled climate systems, the climate change in a single model (e.g., Zheng et al. 2011) may be dominated by internal variability rather than GHG-forced global warming. Our results based on 30 models are consistent with Jiang et al. (2018), which are based on 18 selected models, suggesting that the ensemble of 18 models is sufficient to remove the internal variability. But the proposed mechanism in this study is completely different from Jiang et al. (2018) who emphasized the contribution from the changes of SSTA over WNP and the weakened SSTA gradient between
TIO and WNP. Our mechanism does not rely on the change in SSTA but highlights that the weakened impact of TIO SSTA on the atmosphere can result in a substantially weakened anomalous WNPAC under a warmer climate. It is possible that both mechanisms are at work, and quantitative assessment is needed in the future to assess the relative contributions from these two mechanisms.

Acknowledgments. The authors wish to acknowledge the three anonymous reviewers for their constructive comments, which helped to improve the quality of the current research. This work was supported by National Natural Science Foundation of China (41875081 and 41505067) and National Key Research and Development Program of China (2017YFA0604601 and 2017YFA0603802). Chao He wishes to thank Prof. Masahiro Watanabe for offering the LBM code.

\section{REFERENCES}

Cash, B. A., and Coauthors, 2017: Sampling variability and the changing ENSO-monsoon relationship. Climate Dyn., 48, 4071-4079, https://doi.org/10.1007/s00382-016-3320-3.

Chakravorty, S., J. S. Chowdary, and C. Gnanaseelan, 2014: Epochal changes in the seasonal evolution of tropical Indian Ocean warming associated with El Niño. Climate Dyn., 42, 805-822, https://doi.org/10.1007/s00382-013-1666-3.

Chang, C. P., Y. S. Zhang, and T. Li, 2000: Interannual and interdecadal variations of the East Asian summer monsoon and tropical Pacific SSTs. Part I: Roles of the subtropical ridge. J. Climate, 13, 4310-4325, https://doi.org/10.1175/ 1520-0442(2000)013<4310:IAIVOT > 2.0.CO;2.

Chen, J., X. Wang, W. Zhou, and Z. Wen, 2018: Interdecadal change in the summer SST-precipitation relationship around the late 1990s over the South China Sea. Climate Dyn., 51, 2229-2246, https:// doi.org/10.1007/s00382-017-4009-y.

Chen, W., J. K. Park, B. W. Dong, R. Y. Lu, and W. S. Jung, 2012: The relationship between El Niño and the western North Pacific summer climate in a coupled GCM: Role of the transition of El Niño decaying phases. J. Geophys. Res., 117, D12111, https:// doi.org/10.1029/2011JD017385.

_ , J.-Y. Lee, K.-J. Ha, K.-S. Yun, and R. Lu, 2016: Intensification of the western North Pacific anticyclone response to the short decaying El Niño event due to greenhouse warming. J. Climate, 29, 3607-3627, https://doi.org/10.1175/JCLI-D-15-0195.1.

Chen, X., and T. Zhou, 2018: Relative contributions of external SST forcing and internal atmospheric variability to July-August heat waves over the Yangtze River valley. Climate Dyn., 51, 4403-4419, https://doi.org/10.1007/s00382-017-3871-y.

Chen, Z., Z. Wen, R. Wu, X. Lin, and J. Wang, 2016: Relative importance of tropical SST anomalies in maintaining the western North Pacific anomalous anticyclone during El Niño to La Niña transition years. Climate Dyn., 46, 1027-1041, https://doi.org/ 10.1007/s00382-015-2630-1.

Chiang, J. C. H., and A. H. Sobel, 2002: Tropical tropospheric temperature variations caused by ENSO and their influence on the remote tropical climate. J. Climate, 15, 2616-2631, https:// doi.org/10.1175/1520-0442(2002)015<2616:TTTVCB >2.0.CO;2. 
_ and B. R. Lintner, 2005: Mechanisms of remote tropical surface warming during El Niño. J. Climate, 18, 4130-4149, https://doi.org/ 10.1175/JCLI3529.1.

Chowdary, J. S., S. P. Xie, H. Tokinaga, Y. M. Okumura, H. Kubota, N. Johnson, and X. T. Zheng, 2012: Interdecadal variations in ENSO teleconnection to the Indo-Western Pacific for 1870-2007. J. Climate, 25, 1722-1744, https://doi.org/ 10.1175/JCLI-D-11-00070.1.

Deser, C., A. Phillips, V. Bourdette, and H. Teng, 2012: Uncertainty in climate change projections: The role of internal variability. Climate Dyn., 38, 527-546, https://doi.org/10.1007/ s00382-010-0977-x.

Du, Y., S. Xie, G. Huang, and K. Hu, 2009: Role of air-sea interaction in the long persistence of El Niño-induced North Indian Ocean warming. J. Climate, 22, 2023-2038, https://doi.org/ 10.1175/2008JCLI2590.1.

Gleckler, P. J., K. E. Taylor, and C. Doutriaux, 2008: Performance metrics for climate models. J. Geophys. Res., 113, D06104, https:// doi.org/10.1029/2007JD008972.

Gu, B., Z. Zheng, G. Feng, and X. Wang, 2017: Interdecadal transition in the relationship between the western Pacific subtropical high and sea surface temperature. Int. J. Climatol., 37, 2667-2678, https://doi.org/10.1002/joc.4872.

He, C., and T. Zhou, 2014: The two interannual variability modes of the western North Pacific subtropical high simulated by 28 CMIP5-AMIP models. Climate Dyn., 43, 2455-2469, https:// doi.org/10.1007/s00382-014-2068-x.

- and - 2015: Decadal change of the connection between summer western North Pacific subtropical high and tropical SST in the early 1990s. Atmos. Sci. Lett., 16, 253-259, https:// doi.org/10.1002/asl2.550.

- _ _ and B. Wu, 2015: The key oceanic regions responsible for the interannual variability of the western North Pacific subtropical high and associated mechanisms. J. Meteor. Res., 29, 562-575, https://doi.org/10.1007/s13351-015-5037-3.

—, A. Lin, D. Gu, C. Li, B. Zheng, B. Wu, and T. Zhou, 2018: Using eddy geopotential height to measure the western North Pacific subtropical high in a warming climate. Theor. Appl. Climatol., 131, 681-691, https://doi.org/10.1007/s00704-016-2001-9.

Hong, C.-C., T.-C. Chang, and H.-H. Hsu, 2014: Enhanced relationship between the tropical Atlantic SST and the summertime western North Pacific subtropical high after the early 1980s. J. Geophys. Res. Atmos., 119, 3715-3722, https://doi.org/ 10.1002/2013JD021394.

Hu, K., G. Huang, X.-T. Zheng, S.-P. Xie, X. Qu, Y. Du, and L. Liu, 2014: Interdecadal variations in ENSO influences on Northwest Pacific-East Asian early summertime climate simulated in CMIP5 models. J. Climate, 27, 5982-5998, https://doi.org/ 10.1175/JCLI-D-13-00268.1.

Hu, X., M. Cai, S. Yang, and Z. Wu, 2018: Delineation of thermodynamic and dynamic responses to sea surface temperature forcing associated with El Niño. Climate Dyn., 51, 4329-4344, https://doi.org/10.1007/s00382-017-3711-0.

Huang, B., and Coauthors, 2017: Extended Reconstructed Sea Surface Temperature, Version 5 (ERSSTv5): Upgrades, validations, and intercomparisons. J. Climate, 30, 8179-8205, https://doi.org/10.1175/JCLI-D-16-0836.1.

Huang, G., K. M. Hu, and S. P. Xie, 2010: Strengthening of tropical Indian Ocean teleconnection to the Northwest Pacific since the mid-1970s: An atmospheric GCM study. J. Climate, 23, 5294-5304, https://doi.org/10.1175/2010JCLI3577.1.

Huang, P., D. Chen, and J. Ying, 2017: Weakening of the tropical atmospheric circulation response to local sea surface temperature anomalies under global warming. J. Climate, 30, 8149-8158, https://doi.org/10.1175/JCLI-D-17-0171.1.

Huang, R. H., and F. Y. Sun, 1992: Impacts of the tropical western Pacific on the East Asian Summer Monsoon. J. Meteor. Soc. Japan, 70, 243-256, https://doi.org/10.2151/jmsj1965.70.1B_243.

Huang, Y., H. Wang, K. Fan, and Y. Gao, 2015: The western Pacific subtropical high after the 1970s: Westward or eastward shift? Climate Dyn., 44, 2035-2047, https://doi.org/10.1007/s00382-014-2194-5.

Hurrell, J. W., J. J. Hack, D. Shea, J. M. Caron, and J. Rosinski, 2008: A new sea surface temperature and sea ice boundary dataset for the Community Atmosphere Model. J. Climate, 21, 5145-5153, https://doi.org/10.1175/2008JCLI2292.1.

IPCC, 2013: Climate Change 2013: The Physical Science Basis. Cambridge University Press, 1535 pp., https://doi.org/10.1017/ CBO9781107415324.

Jiang, W., G. Huang, P. Huang, and K. Hu, 2018: Weakening of northwest Pacific anticyclone anomalies during post-El Niño summers under global warming. J. Climate, 31, 3539-3555, https://doi.org/10.1175/JCLI-D-17-0613.1.

Jin, Q., X.-Q. Yang, X.-G. Sun, and J.-B. Fang, 2013: East Asian summer monsoon circulation structure controlled by feedback of condensational heating. Climate Dyn., 41, 1885-1897, https://doi.org/10.1007/s00382-012-1620-9.

Johnson, N. C., and S.-P. Xie, 2010: Changes in the sea surface temperature threshold for tropical convection. Nat. Geosci., 3, 842-845, https://doi.org/10.1038/ngeo1008.

Kalnay, E., and Coauthors, 1996: The NCEP/NCAR 40-Year Reanalysis Project. Bull. Amer. Meteor. Soc., 77, 437-471, https:// doi.org/10.1175/1520-0477(1996)077<0437:TNYRP>2.0.CO;2.

Kumar, A., and Z.-Z. Hu, 2012: Uncertainty in the oceanatmosphere feedbacks associated with ENSO in the reanalysis products. Climate Dyn., 39, 575-588, https://doi.org/ 10.1007/s00382-011-1104-3.

Li, S. L., J. Lu, G. Huang, and K. M. Hu, 2008: Tropical Indian Ocean basin warming and East Asian summer monsoon: A multiple AGCM study. J. Climate, 21, 6080-6088, https://doi.org/10.1175/ 2008JCLI2433.1.

Li, T., B. Wang, B. Wu, and T. Zhou, 2017: Theories on formation of an anomalous anticyclone in western North Pacific during El Niño: A review. J. Meteor. Res., 31, 987-1006, https://doi.org/ 10.1007/s13351-017-7147-6.

Li, X., W. Zhou, D. Chen, C. Li, and J. Song, 2014: Water vapor transport and moisture budget over eastern China: Remote forcing from the two types of El Niño. J. Climate, 27, 87788792, https://doi.org/10.1175/JCLI-D-14-00049.1.

Neale, R. B., and Coauthors, 2012: Description of the NCAR Community Atmosphere Model (CAM 5.0). NCAR Tech. Note NCAR/TN-486+STR, 274 pp., www.cesm.ucar.edu/ models/cesm1.0/cam/docs/description/cam5_desc.pdf.

Nitta, T., 1987: Convective activities in the tropical western Pacific and their impact on the Northern Hemisphere summer circulation. J. Meteor. Soc. Japan, 65, 373-390, https://doi.org/ 10.2151/jmsj1965.65.3_373.

Power, S. B., F. Delage, R. Colman, and A. Moise, 2012: Consensus on twenty-first-century rainfall projections in climate models more widespread than previously thought. J. Climate, 25, 3792-3809, https://doi.org/10.1175/JCLI-D-11-00354.1.

Rong, X., R. Zhang, and T. Li, 2010: Impacts of Atlantic sea surface temperature anomalies on Indo-East Asian summer monsoonENSO relationship. Chin. Sci. Bull., 55, 2458-2468, https://doi. org/10.1007/s11434-010-3098-3.

Song, F., and T. Zhou, 2014a: Interannual variability of East Asian summer monsoon simulated by CMIP3 and CMIP5 AGCMs: Skill 
dependence on Indian Ocean-western Pacific anticyclone teleconnection. J. Climate, 27, 1679-1697, https://doi.org/10.1175/ JCLI-D-13-00248.1.

- - and - - 2014b: The climatology and interannual variability of East Asian summer monsoon in CMIP5 coupled models: Does air-sea coupling improve the simulations? J. Climate, 27, 8761-8777, https://doi.org/10.1175/JCLI-D-14-00396.1. , and -2015 : The crucial role of internal variability in modulating the decadal variation of the East Asian summer monsoonENSO relationship during the twentieth century. J. Climate, 28, 7093-7107, https://doi.org/10.1175/JCLI-D-14-00783.1.

Stevenson, S., B. Fox-Kemper, M. Jochum, R. Neale, C. Deser, and G. Meehl, 2012: Will there be a significant change to El Niño in the twenty-first century? J. Climate, 25, 2129-2145, https://doi.org/ 10.1175/JCLI-D-11-00252.1.

Stuecker, M. F., F.-F. Jin, A. Timmermann, and S. McGregor, 2015: Combination mode dynamics of the anomalous northwest Pacific anticyclone. J. Climate, 28, 1093-1111, https://doi.org/ 10.1175/JCLI-D-14-00225.1.

Sui, C. H., P. H. Chung, and T. Li, 2007: Interannual and interdecadal variability of the summertime western North Pacific subtropical high. Geophys. Res. Lett., 34, L11701, https://doi.org/10.1029/ 2006GL029204.

Tao, W., G. Huang, K. Hu, X. Qu, G. Wen, and H. Gong, 2015: Interdecadal modulation of ENSO teleconnections to the Indian Ocean Basin Mode and their relationship under global warming in CMIP5 models. Int. J. Climatol., 35, 391-407, https://doi.org/10.1002/joc.3987.

Taylor, K. E., R. J. Stouffer, and G. A. Meehl, 2012: An overview of CMIP5 and the experiment design. Bull. Amer. Meteor. Soc., 93, 485-498, https://doi.org/10.1175/BAMS-D-11-00094.1.

Terao, T., and T. Kubota, 2005: East-west SST contrast over the tropical oceans and the post El Niño western North Pacific summer monsoon. Geophys. Res. Lett., 32, L15706, https://oi.org/10.1029/ 2005 GL023010.

van Vuuren, D., and Coauthors, 2011: The representative concentration pathways: An overview. Climatic Change, 109, 531, https://doi.org/10.1007/s10584-011-0148-z.

Wang, B., R. G. Wu, and X. H. Fu, 2000: Pacific-East Asian teleconnection: How does ENSO affect East Asian climate? J. Climate, 13, 1517-1536, https://doi.org/10.1175/1520-0442(2000)013<1517: PEATHD $>2.0 . \mathrm{CO} ; 2$

_ _ B. Xiang, and J.-Y. Lee, 2013: Subtropical high predictability establishes a promising way for monsoon and tropical storm predictions. Proc. Natl. Acad. Sci. USA, 110, 2718-2722, https:// doi.org/10.1073/pnas.1214626110.

Watanabe, M., and M. Kimoto, 2000: Atmosphere-ocean thermal coupling in the North Atlantic: A positive feedback. Quart. J. Roy. Meteor. Soc., 126, 3343-3369, https://doi.org/10.1002/ qj. 49712657017.

Wu, B., and T. Zhou, 2016: Relationships between ENSO and the East Asian-western North Pacific monsoon: Observations versus 18 CMIP5 models. Climate Dyn., 46, 729-743, https:// doi.org/10.1007/s00382-015-2609-y.

— , T. J. Zhou, and T. Li, 2009a: Seasonally evolving dominant interannual variability modes of East Asian climate. J. Climate, 22, 2992-3005, https://doi.org/10.1175/2008JCLI2710.1. ,$--\frac{-}{-}$ and,$- 2009 \mathrm{~b}$ : Contrast of rainfall-SST relationships in the western North Pacific between the ENSO-developing and ENSO-decaying summers. J. Climate, 22, 4398-4405, https://doi.org/10.1175/2009JCLI2648.1.

— , T. Li, and T. J. Zhou, 2010: Relative contributions of the Indian Ocean and local SST anomalies to the maintenance of the western North Pacific anomalous anticyclone during the El Niño decaying summer. J. Climate, 23, 2974-2986, https:// doi.org/10.1175/2010JCLI3300.1.

—, T. Zhou, and T. Li, 2017: Atmospheric dynamic and thermodynamic processes driving the western North Pacific anomalous anticyclone during El Niño. Part I: Maintenance mechanisms. J. Climate, 30, 9621-9635, https://doi.org/10.1175/ JCLI-D-16-0489.1.

Xiang, B., B. Wang, W. Yu, and S. Xu, 2013: How can anomalous western North Pacific subtropical high intensify in late summer? Geophys. Res. Lett., 40, 2349-2354, https://doi.org/ 10.1002/grl.50431.

Xie, S.-P., K. M. Hu, J. Hafner, H. Tokinaga, Y. Du, G. Huang, and T. Sampe, 2009: Indian Ocean capacitor effect on Indo-western Pacific climate during the summer following El Niño. J. Climate, 22, 730-747, https://doi.org/10.1175/2008JCLI2544.1.

—_, Y. Du, G. Huang, X. T. Zheng, H. Tokinaga, K. M. Hu, and Q. Y. Liu, 2010: Decadal shift in El Niño influences on Indo-western Pacific and East Asian climate in the 1970s. J. Climate, 23, 3352-3368, https://doi.org/10.1175/ 2010JCLI3429.1.

_- Y. Kosaka, Y. Du, K. Hu, J. S. Chowdary, and G. Huang, 2016: Indo-western Pacific Ocean capacitor and coherent climate anomalies in post-ENSO summer: A review. Adv. Atmos. Sci. 33, 411-432, https://doi.org/10.1007/s00376-015-5192-6.

Yanai, M., and T. Tomita, 1998: Seasonal and interannual variability of atmospheric heat sources and moisture sinks as determined from NCEP-NCAR reanalysis. J. Climate, 11, 463-482, https://doi.org/ 10.1175/1520-0442(1998)011<0463:SAIVOA > 2.0.CO;2.

Yang, J. L., Q. Y. Liu, S. P. Xie, Z. Y. Liu, and L. X. Wu, 2007 Impact of the Indian Ocean SST basin mode on the Asian summer monsoon. Geophys. Res. Lett., 34, L02708, https:// doi.org/10.1029/2006GL028571.

Zhang, R. H., A. Sumi, and M. Kimoto, 1999: A diagnostic study of the impact of El Niño on the precipitation in China. $A d v$ Atmos. Sci., 16, 229-241, https://doi.org/10.1007/BF02973084.

_, Q. Min, and J. Su, 2017: Impact of El Niño on atmospheric circulations over East Asia and rainfall in China: Role of the anomalous western North Pacific anticyclone. Sci. China Earth Sci., 60, 1124, https://doi.org/10.1007/s11430-016-9026-x.

Zhang, W., and Coauthors, 2016: Unraveling El Niño's impact on the East Asian Monsoon and Yangtze River summer flooding. Geophys. Res. Lett., 43, 11375-11382, https://doi.org/10.1002/ 2016GL071190.

Zheng, X. T., S. P. Xie, and Q. Y. Liu, 2011: Response of the Indian Ocean basin mode and its capacitor effect to global warming. J. Climate, 24, 6146-6164, https://doi.org/10.1175/ 2011JCLI4169.1.

— - - L.-H. Lv, and Z.-Q. Zhou, 2016: Intermodel uncertainty in ENSO amplitude change tied to Pacific Ocean warming pattern. J. Climate, 29, 7265-7279, https://doi.org/10.1175/ JCLI-D-16-0039.1. 